\title{
A matter of divergence: Tracking recent warming at hemispheric scales using tree ring data
}

\author{
R. Wilson, ${ }^{1,2}$ R. D’Arrigo, ${ }^{2}$ B. Buckley, ${ }^{2}$ U. Büntgen, ${ }^{3}$ J. Esper, ${ }^{3}$ D. Frank, ${ }^{3}$ B. Luckman, ${ }^{4}$ \\ S. Payette, ${ }^{5}$ R. Vose, ${ }^{6}$ and D. Youngblut ${ }^{7}$ \\ Received 6 December 2006; revised 20 March 2007; accepted 8 May 2007; published 11 September 2007.
}

[1] No current tree ring (TR) based reconstruction of extratropical Northern Hemisphere (ENH) temperatures that extends into the 1990s captures the full range of late 20th century warming observed in the instrumental record. Over recent decades, a divergence between cooler reconstructed and warmer instrumental large-scale temperatures is observed. We hypothesize that this problem is partly related to the fact that some of the constituent chronologies used for previous reconstructions show divergence against local temperatures in the recent period. In this study, we compiled TR data and published local/regional reconstructions that show no divergence against local temperatures. These data have not been included in other large-scale temperature reconstructions. Utilizing this data set, we developed a new, completely independent reconstruction of ENH annual temperatures (1750-2000). This record is not meant to replace existing reconstructions but allows some degree of independent validation of these earlier studies as well as demonstrating that TR data can better model recent warming at large scales when careful selection of constituent chronologies is made at the local scale. Although the new series tracks the increase in ENH annual temperatures over the last few decades better than any existing reconstruction, it still slightly under predicts values in the post-1988 period. We finally discuss possible reasons why it is so difficult to model post-mid-1980s warming, provide some possible alternative approaches with regards to the instrumental target and detail several recommendations that should be followed in future large-scale reconstruction attempts that may result in more robust temperature estimates.

Citation: Wilson, R., R. D’Arrigo, B. Buckley, U. Büntgen, J. Esper, D. Frank, B. Luckman, S. Payette, R. Vose, and D. Youngblut (2007), A matter of divergence: Tracking recent warming at hemispheric scales using tree ring data, J. Geophys. Res., 112, D17103, doi:10.1029/2006JD008318.

\section{Introduction}

[2] It is an unfortunate fact that no existing tree ring (TR) based reconstruction of extratropical Northern Hemisphere (ENH) temperatures, that extends into the 1990s, can model the full magnitude of late 20th century warming [e.g., Briffa, 2000; Esper et al., 2002; D'Arrigo et al., 2006]. These ring width based proxy reconstructions show, since approximately the mid-1980s, a divergence between largescale reconstructed (cooler) and instrumental (warmer)

\footnotetext{
${ }^{1}$ Grant Institute, University of Edinburgh, Edinburgh, UK.

${ }^{2}$ Lamont-Doherty Earth Observatory, Palisades, New York, USA

${ }^{3}$ Swiss Federal Research Institute WSL, Birmensdorf, Switzerland.

${ }^{4}$ Department of Geography, University of Western Ontario, London, Ontario, Canada.

${ }^{5}$ Centre d'Études Nordiques, Université Laval, Québec, Quebec, Canada.

${ }^{6}$ National Climatic Data Center, Asheville, North Carolina, USA.

${ }^{7}$ Department of Geography and Environmental Studies, Carleton University, Ottawa, Ontario, Canada.
}

Copyright 2007 by the American Geophysical Union. 0148-0227/07/2006JD008318 temperatures (Figure 1). This divergence, however, is not as significant as the underprediction noted for TR maximum density based large-scale reconstructions [Briffa et al., 2001] which start diverging around the 1960s. This failure in tracking recent temperature trends, with the 1990s purported to be the warmest decade for the last four centuries [National Research Council (NRC), 2006] and possibly the last millennium, questions the ability of such large-scale TR based reconstructions to provide robust estimates of earlier warm intervals (e.g., the Medieval Warm Period). This "breakdown" of calibration in the recent period is popularly known as the "divergence problem." This phenomenon (see D'Arrigo et al. [2007] for a more detailed discussion) is herein defined as the tendency for tree growth at some previously temperature-limited sites to demonstrate a weakening in mean temperature response in recent decades, with the divergence being expressed as a loss in climate sensitivity and/or a divergence in trend. Several studies have described this issue at different spatial scales and for various regions and species [Jacoby and D'Arrigo, 1995; Briffa et al., 1998a, 1998b; Vaganov et al., 1999; Barber et al., 2000; Briffa, 2000; Jacoby et al., 2000; 


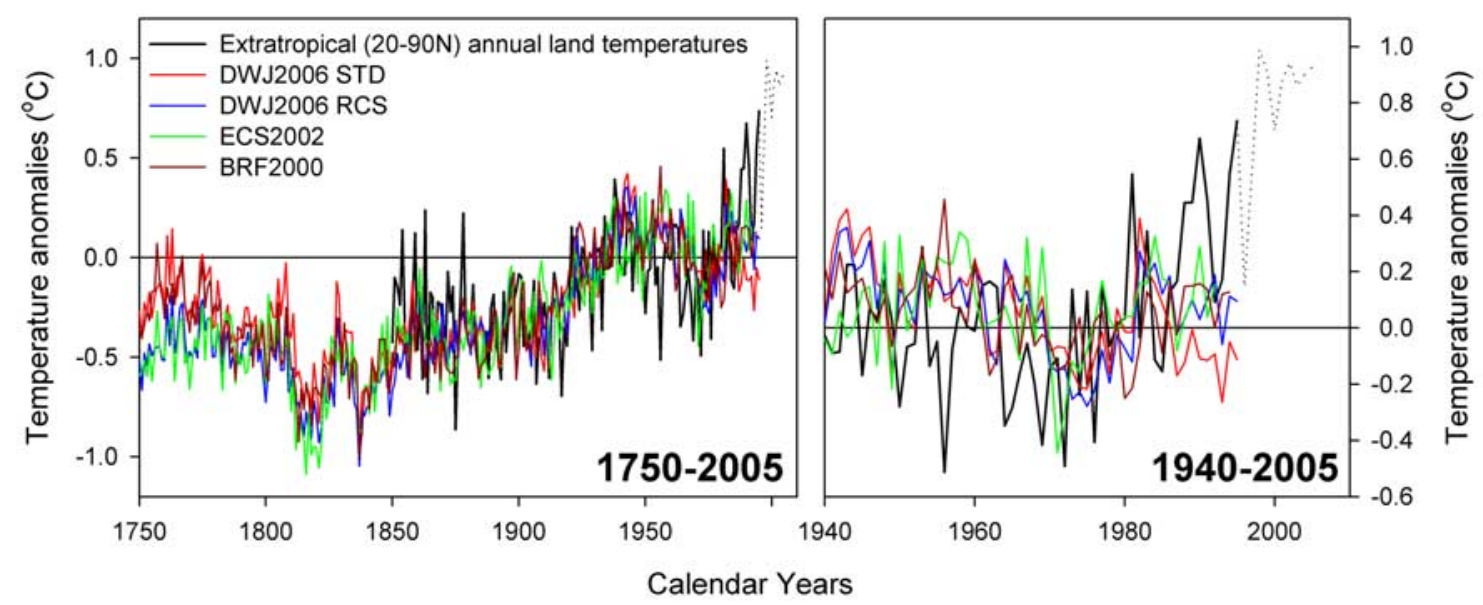

Figure 1. Tree ring based reconstructions of ENH temperatures. The series have been scaled to mean annual land $\left(20-90^{\circ} \mathrm{N}\right)$ extratropical temperatures over the $1850-1988$ period. The plot on the right shows the last $\sim 60$ years and highlights the underprediction of reconstructed values since approximately the mid-1980s. The post-1995 period in the instrumental data is portrayed using a dotted series so as not to incur a visual bias with regards to recent divergence. The DWJ2006 reconstructions are detailed by D'Arrigo et al. [2006], and the ECS2002 reconstructions are detailed by Esper et al. [2002]. The BRF2000 series [Briffa, 2000] series was truncated at 1994, after which replication was less than three TR chronologies.

Lloyd and Fastie, 2002; Wilson and Luckman, 2003; Briffa et al., 2004; D'Arrigo et al., 2004; Wilmking et al., 2004, 2005; Driscoll et al., 2005; Büntgen et al., 2006a; Carrer and Urbinati, 2006]. This collection of studies supports the notion [Briffa et al., 1998a, 1998b] that there has been a widespread drift, over recent decades, in the ecophysiological response of tree growth to climate across the Northern Hemisphere. It has been suggested that this phenomenon appears to be largely confined to higher-latitude northern forests [e.g., Briffa et al., 1998a; Cook et al., 2004]. However, the relative scarcity of ring width and density records from the lower midlatitudes, tropics and Southern Hemisphere precludes making definitive conclusions about the spatial extent of this phenomenon, and further research is needed to more fully evaluate the extent of the divergence problem worldwide [D'Arrigo et al., 2007]. The causes of the divergence are also not well understood and are difficult to test because of the existence of several covarying environmental factors that may potentially impact recent tree growth. Some suggested causative factors from local/ regional studies include temperature-induced drought stress [Jacoby and D'Arrigo, 1995; Barber et al., 2000; Lloyd and Fastie, 2002; Büntgen et al., 2006a], complex nonlinear responses [Vaganov et al., 1999; D'Arrigo et al., 2004], local pollution [Wilson and Elling, 2004; Yonenobu and Eckstein, 2006], differential growth response to maximum, minimum and mean temperatures [Wilson and Luckman, 2002, 2003] and "end effect" issues related to the detrending of TR data [Melvin, 2004; K. Briffa and T. Melvin, Climatic Research Unit, personal communication, 2006]. The TR based reconstruction that expresses the greatest divergence is the STD version of D'Arrigo et al. [2006, Figure 1]. This highlights the potential bias that may occur from using "traditional" individual series detrending approaches. Large-scale causes may be related to changes in stratospheric ozone concentration [Briffa et al., 2004] or the effects upon photosynthesis rates of the global dimming phenomenon [D'Arrigo et al., 2007]. Although limited evidence suggests that the cause of the divergence is anthropogenic in nature and restricted to the latter end of the 20th century [Cook et al., 2004], more research is needed to confirm this hypothesis. To complicate the issue, the divergence problem is not observed at all temperature sensitive TR sites. There are numerous local/regional studies that show no divergence between TR chronologies and temperature [Szeicz and MacDonald, 1995; Jacoby et al., 1996; Biondi et al., 1999; D'Arrigo et al., 2000, 2001; Kirchhefer, 2001; Wilson and Luckman, 2002; Cook et al., 2003; Davi et al., 2003 (for density); Wilson and Topham, 2004; Büntgen et al., 2005, 2006b, 2007; Frank and Esper, 2005; Luckman and Wilson, 2005; Salzer and Kipfmueller, 2005; Youngblut and Luckman, 2007].

[3] For the ENH temperature reconstruction of D'Arrigo et al. [2006], some of the constituent TR chronologies expressed divergence at the local scale. It is therefore not surprising that divergence was noted in the resultant hemispheric reconstruction. In this paper we test whether it is possible to develop an ENH reconstruction that better tracks recent temperature trends. We attempt to address the "divergence problem" noted in large-scale reconstructions by developing a new independent TR based reconstruction of ENH temperatures using published local/regional reconstructions and newly updated/sampled TR chronologies that show no divergence against local temperatures. This new record is not meant to replace existing reconstructions, in fact it allows some degree of independent validation of these earlier studies, but rather to quantify and test how much more skillfully TR data can model recent warming at 


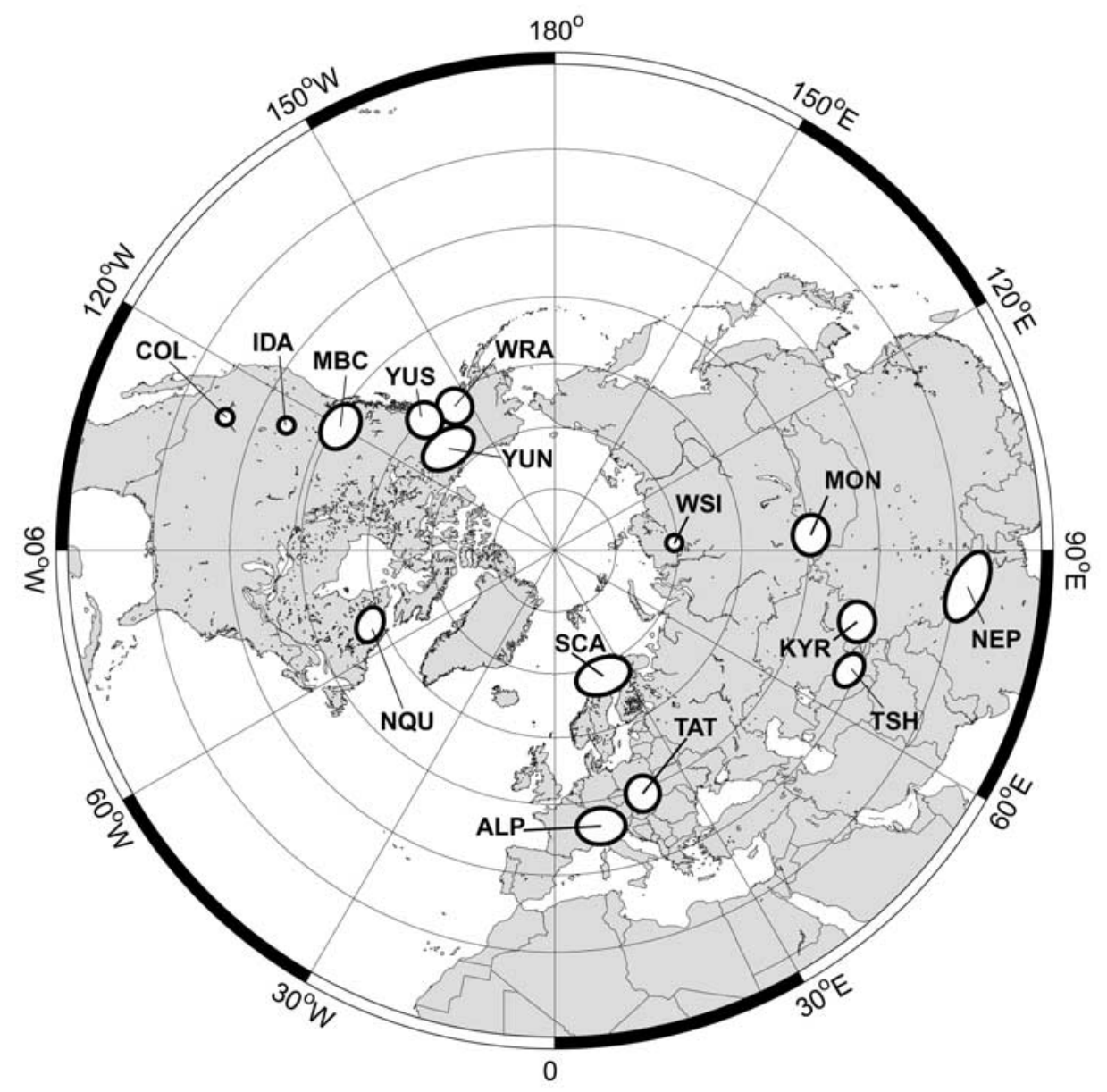

Figure 2. Location map of regional TR proxy records used to reconstruct ENH temperatures for the period 1750-2000. See Table 1 for code description. The size of the semicircle roughly reflects the size of the network from which the proxy record was derived.

large scales when careful selection of constituent chronologies is made.

\section{TR Data Selection}

[4] A number of criteria were defined to assess whether a published reconstruction or TR chronology would be considered for analysis:

[5] 1. To ensure the independence of this study, only TR proxy series that had not been used in previous reconstructions of ENH temperatures would be considered.

[6] 2. As undertaken by D'Arrigo et al. [2006] each TR series must have acceptable replication $(\geq 10$ series within each site chronology) from 1750 to present.

[7] 3. Nonpublished TR data must extend to 1995 or beyond.

[8] 4. The TR proxy series must correlate at $>0.40$ against an optimal seasonal parameter of "local" gridded mean temperature data from the CRU3 [Brohan et al., 2006] land only data set. Even if a series correlates at $<0.40$, but the inferred association is significant at the $95 \%$ confidence limit, it was still rejected from further analysis.

[9] 5. No significant autocorrelation (as measured using the Durbin-Watson statistic) must be observed in the model residuals from regressing the TR proxy time series against the local seasonal temperature data. If a significant divergence exists between the TR data and local temperatures, this would be expressed as trend in the model residuals and hence they would be autocorrelated.

[10] By strict observance to these criteria, we identified 15 TR based temperature proxy series (Figure 2 and Table 1) that portray reasonable estimates of "local" temperatures. 12 of these series are published reconstructions. Four (ALP, SCA, MON and MBC) of these published series have been "updated" or "reprocessed" for this study. A further three sites (WSI, KYR and NQU) were added to the hemispheric data set by using unpublished TR data acquired from either the International Tree ring Data-bank (http:// www.ncdc.noaa.gov/paleo/treering.html) or nonarchived sources. Although a minimum of only 10 series were defined as acceptable, the signal strength (as measured using the Expressed Population Signal statistic [Briffa and Jones, 1990]) is strong in all of these series from 1750 onward. The time series for each of these 15 temperature TR proxies can be accessed in the auxiliary material ${ }^{1}$ and Appendix A briefly describes how each series was derived.

\footnotetext{
${ }^{1}$ Auxiliary materials are available at $\mathrm{ftp}: / / \mathrm{ftp}$.agu.org/apend/jd/ 2006jd008318.
} 
[11] It should be noted that two published TR reconstructions that meet the post- 1750 replication screening criterion were not used for this study as they failed selection because of calibration issues. These series are the reconstructions from (1) Hokkaido (1557-1997 [Davi et al., 2002]) which, although correlating significantly at high frequencies with local gridded August-September temperatures $(r=0.48$ (1876-1997), after the data had been transformed to $1 \mathrm{st}$ differences), expresses serious trend differences between the TR and instrumental data (before $\sim 1920$ and after $\sim 1980$ ) that result in significant autocorrelation in the model residuals (see Davi et al. [2002] for more discussion where the time series was purposely interpreted to provide highfrequency climatic information only for the region); and (2) Kamchatka (1630-1992 [Gostev et al., 1996]) which correlates poorly $(\mathrm{r}=0.25,1906-1992)$ with local gridded temperatures despite the much stronger published correlation $(r=0.63,1942-1983)$ noted against the nearest meteorological station (Esso [Gostev et al., 1996]).

\section{Reconstruction Method}

[12] We employ a similar method to that used by D'Arrigo et al. [2006] to derive a new ENH annual temperature reconstruction. Averaging was performed to composite the TR proxy time series into continental and $\mathrm{NH}$ mean series, which were used to calibrate against the instrumental record. A nested approach, which accounts for the decrease in the number of chronologies (in this case forward in time), was used to extend the reconstruction as far forward as possible [Meko, 1997; Cook et al., 2002]. This procedure entails normalizing the TR time series to the common period of all series in each nest and then averaging the series together to create a nest mean. To develop the final reconstruction, the mean and variance of each nested time series were scaled to that of the most replicated nest (1750-1988) and the relevant sections for each nest spliced together. For each nest, separate average time series were generated for North America and Eurasia and these continental-scale time series were averaged to produce a final large-scale mean that was not biased to one particular continent because of the varying number of series. This process, undertaken iteratively as each TR time series left the data matrix, resulted in eight nested mean series upon which calibration and verification were made separately. Following a similar approach as D'Arrigo et al. [2006], full period calibration, against extratropical $\left(20-90^{\circ} \mathrm{N}\right)$ landonly mean annual (January-December) temperatures, was made over 1850-1988 (the common period of the TR and instrumental series), while verification was made over the period 1896-1942 after appropriate calibration using the combined $1850-1895 / 1943-1988$ period. Verification was made using the square of the Pearson's correlation coefficient (r2), the Reduction of Error (RE) statistic and the Coefficient of Efficiency (CE) statistic [Cook and Kairiukstis, 1990; Cook et al., 1994]. Both RE and CE are measures of shared variance between the actual and modeled series, but are usually lower than the calibration r2. A positive value for either statistic signifies that the regression model has some skill. CE provides the more rigorous verification test. To test the robustness of the decadal to long-term signal in the reconstructed nested 
EURASIA

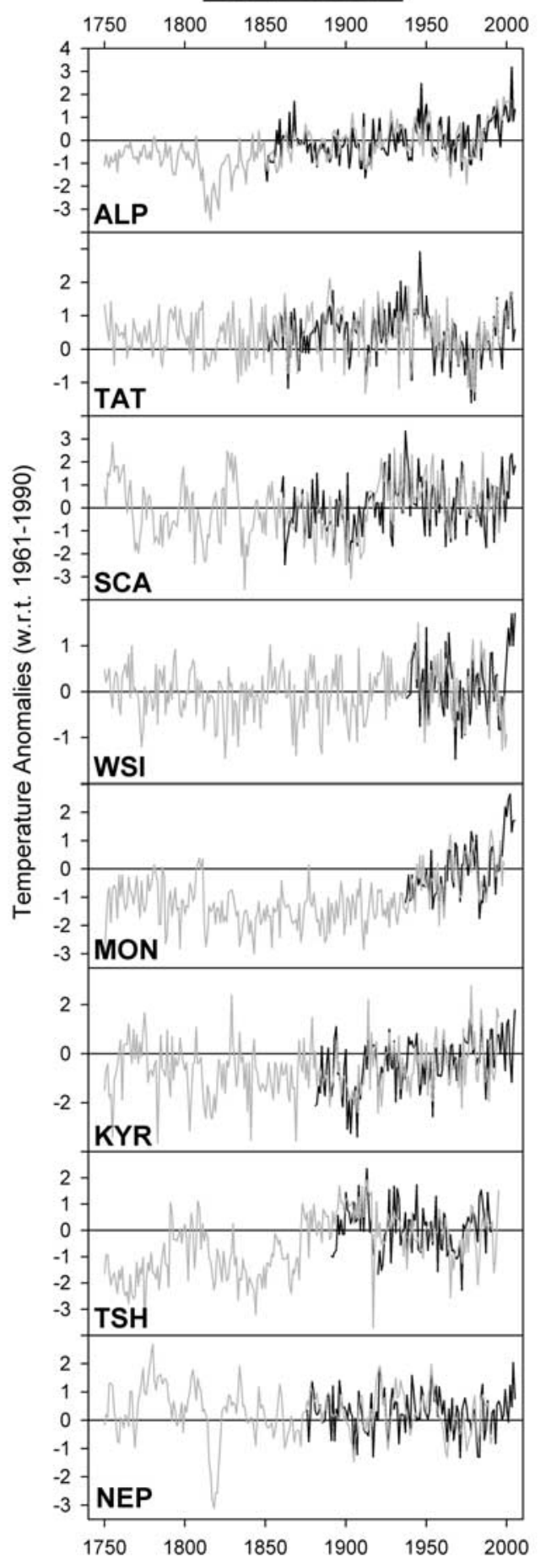

NORTH AMERICA
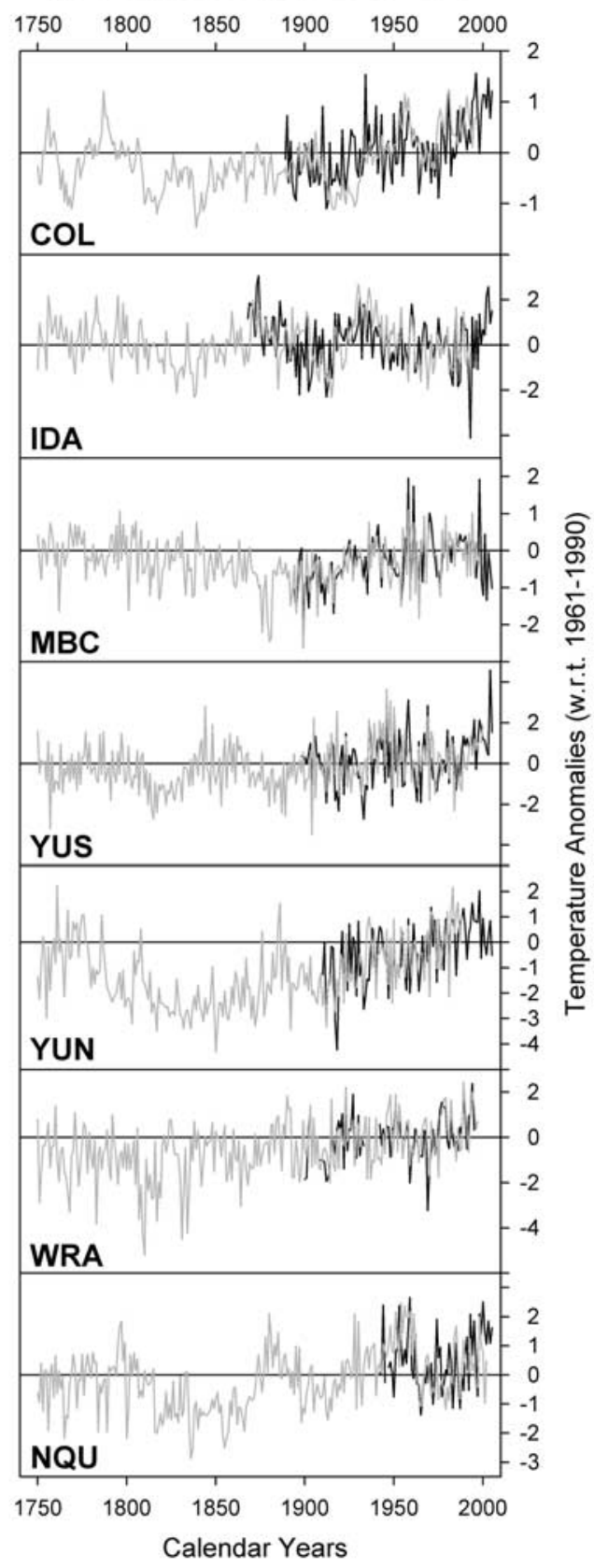

Figure 3. Individual regional composite TR series (see Figure 1 for their locations and Table 1 for code description) scaled to the optimal season of their respective local/regional gridded temperature [Brohan et al., 2006] data set. See Table 1 for coherence statistics between the TR and instrumental data. 
Table 2. Calibration and Verification Results for Each Nested Model ${ }^{\mathrm{a}}$

\begin{tabular}{|c|c|c|c|c|c|c|c|c|c|c|c|c|}
\hline & \multirow[b]{2}{*}{ Relevant Years } & \multirow{2}{*}{$\begin{array}{l}\text { Number } \\
\text { of Series }\end{array}$} & \multicolumn{3}{|c|}{$\begin{array}{c}\text { Full Calibration: } \\
1850-1988 \\
\end{array}$} & \multirow[b]{2}{*}{ Smoothed r2 } & \multicolumn{2}{|c|}{$\begin{array}{c}\text { Calibration: } \\
1850-1895 / \\
1943-1988 \\
\end{array}$} & \multicolumn{3}{|c|}{ Verification: $1896-1942$} & \multirow[b]{2}{*}{$\mathrm{CE}$} \\
\hline & & & $\mathrm{r} 2$ & SE & DW & & $\mathrm{r} 2$ & SE & RMSE & $\mathrm{r} 2$ & $\mathrm{RE}$ & \\
\hline Nest 1 & $1750-1988$ & 15 & 0.25 & 0.23 & 1.74 & 0.71 & 0.20 & 0.25 & 0.24 & 0.40 & 0.37 & 0.37 \\
\hline Nest 2 & $1989-1991$ & 14 & 0.24 & 0.23 & 1.72 & 0.70 & 0.20 & 0.25 & 0.24 & 0.37 & 0.35 & 0.35 \\
\hline Nest 3 & 1992 & 13 & 0.28 & 0.23 & 1.63 & 0.73 & 0.21 & 0.24 & 0.24 & 0.36 & 0.35 & 0.35 \\
\hline Nest 4 & $1993-1995$ & 12 & 0.27 & 0.22 & 1.73 & 0.73 & 0.24 & 0.24 & 0.25 & 0.36 & 0.33 & 0.33 \\
\hline Nest 5 & 1996 & 10 & 0.26 & 0.22 & 1.80 & 0.78 & 0.24 & 0.24 & 0.25 & 0.31 & 0.30 & 0.30 \\
\hline Nest 6 & 1997 & 9 & 0.22 & 0.23 & 1.74 & 0.73 & 0.20 & 0.25 & 0.26 & 0.28 & 0.28 & 0.28 \\
\hline Nest 7 & 1998 & 7 & 0.12 & 0.24 & 1.66 & 0.56 & 0.09 & 0.26 & 0.27 & 0.23 & 0.22 & 0.21 \\
\hline Nest 8 & $1999-2000$ & 6 & 0.12 & 0.24 & 1.60 & 0.50 & 0.07 & 0.26 & 0.26 & 0.27 & 0.24 & 0.23 \\
\hline
\end{tabular}

${ }_{\mathrm{r}}^{\mathrm{a}}$ 2, square of the multiple correlation coefficient; SE, standard error of the estimate; DW, Durbin and Watson statistic for residual autocorrelation; RMSE, root-mean-square error; RE, reduction of error; CE, coefficient of efficiency.

series, assessment of the regression model residuals (from the full period calibration) was also employed using the Durbin-Watson statistic. As the modeled temperature signal is predominantly at timescales $\geq \sim 20$ years [Cook et al., 2004], it is particularly important to identify models that have significant trends in the model residuals, as they would therefore not portray long-term variability in a robust manner.

\section{Results and Discussion}

[13] Table 1 shows the correlation of each of the TR time series against their optimal seasonal parameters of local gridded temperatures. Correlations range from 0.41 (IDA and TSH) to 0.77 (MBC) with an overall mean coherence with local temperatures $>30 \%$. It should be noted that some of the correlations and identified optimal seasons are slightly different to the original publications. This most likely reflects the difference between using gridded versus local temperature records, the latter often providing improved correlation results, as well as identifying the optimal season with respect to the Durbin-Watson statistic results rather than just the correlation coefficient. The fit between the TR and gridded temperature series at local scales can be qualitatively assessed in Figure 3. In all cases, no decadal length divergence occurs for any of the records over the recent period.

[14] The premise of reconstructing large-scale NH temperatures from a relatively sparse network of proxies is that each proxy explains a certain percentage of the local temperature variance, which is itself a constituent part of the large-scale hemispheric mean. Therefore, when these proxy data sets are combined, they theoretically should explain a reasonable amount of the large-scale instrumental temperature variance. However, for a given region or tree ring site, the individual proxy series themselves (and also the instrumental data) may not correlate strongly with $\mathrm{NH}$ temperatures. The last two columns in Table 1 show the correlation of each proxy series with ENH mean annual land only temperatures for both unfiltered and filtered (20-year spline) versions of the data. SCA, MON, MBC and YUN correlate most strongly with $\mathrm{NH}$ temperatures at $\sim 0.30$ (unfiltered). In general, coherence increases substantially when the data are smoothed although some records still correlate poorly. In fact, TAT and TSH are inversely correlated (albeit weakly) with $\mathrm{NH}$ temperatures over the mid-19th to late 20th century period. However, as each of these proxies track relatively well their respective local temperature records (Figure 3), these commonalties in trend (or lack thereof) with the NH instrumental data may simply reflect regional variation in temperatures (see also later discussion).

[15] Table 2 presents the calibration (using ordinary least squares regression) and verification results for each of the eight nested models needed to derive the full $\mathrm{NH}$ reconstruction (1750-2000). Using each of the validation statistics ( $\mathrm{r} 2, \mathrm{RE}$ and $\mathrm{CE}$ ), each nested model passes all verification tests. The $C E$ values are similar to the $R E$ values as the mean of the instrumental data in the verification period $\left(-0.18^{\circ} \mathrm{C}: 1896-1942\right)$ is very close to the mean of the combined calibration period mean $\left(-0.17^{\circ} \mathrm{C}\right.$ : $1850-1895 / 1943-1988)$. The amount of the instrumental temperature variance explained by each nest decreases as the proxy records leave the data matrix. However, in general, up to 1997 the explained variance is around 20$25 \%$ using unfiltered series and $70-75 \%$ using smoothed (20-year spline) series. Although, after 1997, the explained variance drops to $\sim 10 \%$ (50\% for smoothed) for the last two nests, composed of 7 and 6 records respectively, the verification statistics still indicate some fidelity of the models. We therefore, for comparison, utilize the whole length of the reconstruction (1750-2000), with the caveat that the quality of the record decreases after 1988.

[16] Figure 4a compares the new NH reconstruction (hereafter WNH2007) with annual ENH instrumental temperatures after being scaled (same mean and variance) over the 1850-1988 period. As expected from the reasonable calibration/verification results (Table 2), the TR proxy series tracks the trends in the instrumental data quite well. Over the last 250 years, WNH2007 shows moderately cool temperatures until the early 19th century followed by a sharp decline around 1810. Reconstructed temperatures then increase from $\sim 1830$, with decadal-scale variability (i.e., decadal-scale cooling around 1900-1918 and 1961-1976), until present. The coldest decade in WNH2007 is $1812-$ $1821\left(-0.94^{\circ} \mathrm{C}\right)$ which coincides with a period of known volcanic activity (e.g., Tambora, 1815) and low solar irradiance (the Dalton Minimum). The warmest decade is 1989$1998\left(+0.24^{\circ} \mathrm{C}\right)$. WNH2007 shows strong coherence with previous TR based reconstructions of ENH temperatures (Figure 4b) with interproxy correlations $\geq 0.75$ (Table 3 ). 

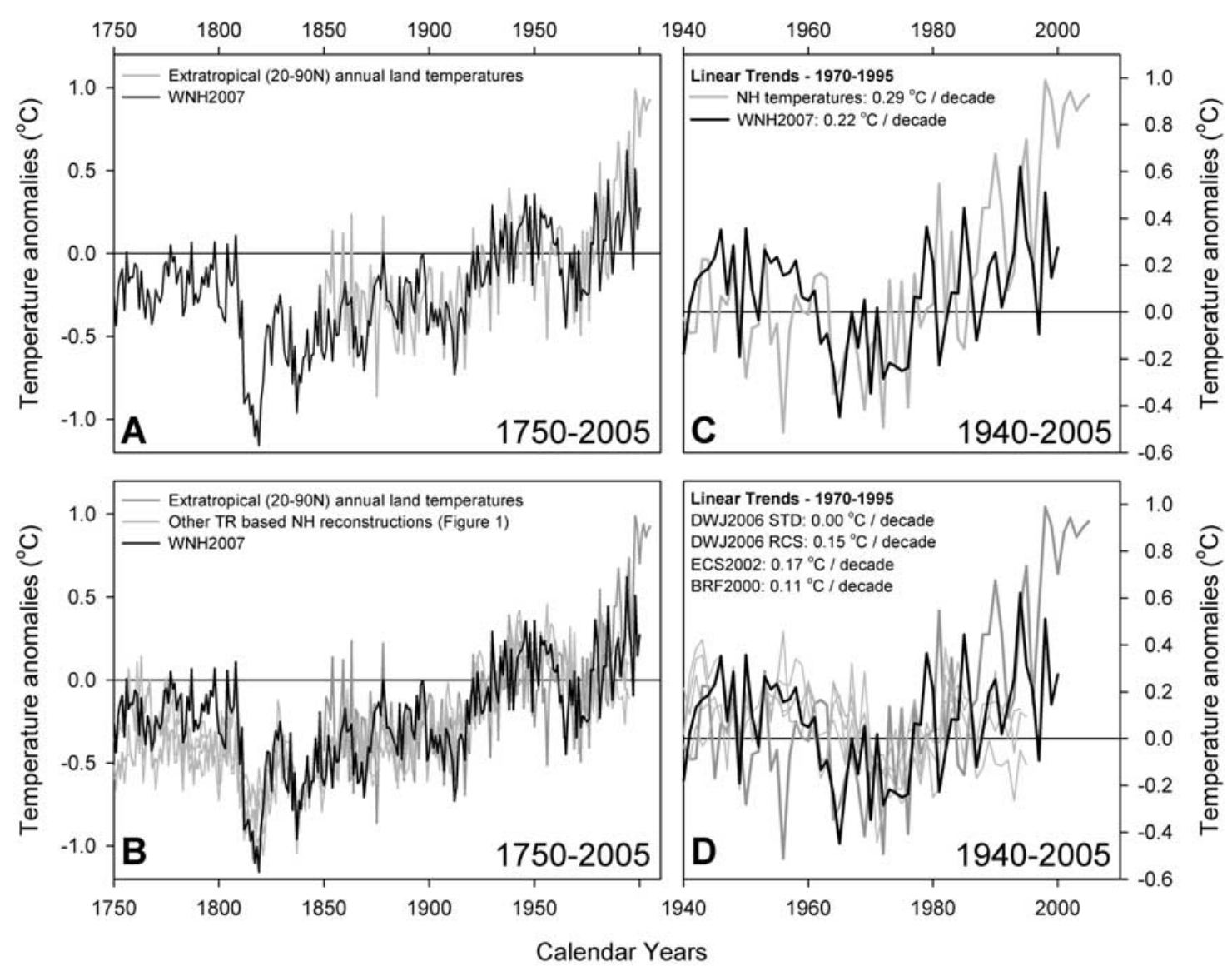

Figure 4. Extratropical instrumental and reconstructed $\left(20-90^{\circ} \mathrm{N}\right) \mathrm{NH}$ annual land temperatures. (a) WNH2007 and instrumental data, 1750-2005. (b) WNH2007, instrumental data and previous TR based extratropical NH reconstructions (see Figure 1), 1750-2005. (c) As Figure 4a but for 1940-2005. Linear trends are calculated for the 1970-1995 period. (d) As Figure 4b but for 1940-2005. Note that although the linear trends are calculated over the 1970-1995 period, the ECS2002 and BRF2000 series only extend to 1992 and 1994, respectively.

WNH2007 has no data overlap with these previous studies, so this strong common signal provides important mutual validation, at least over the last 250 years, of extratropical temperature trends expressed by all these TR based proxies. Focusing on the most recent period (Figure 4c), however, shows that WNH2007 still underpredicts temperature values. Between 1970 and 1995, the linear increase in instrumental temperatures is $0.29^{\circ} \mathrm{C} /$ decade (Figure 4c), compared with $0.22^{\circ} \mathrm{C} /$ decade in the $\mathrm{WNH} 2007$. However, the new reconstruction is still an improvement on earlier attempts (see trends listed in Figure 4d).

[17] Although the WNH2007 reconstruction slightly under predicts values in the post-1988 period, it is the first largescale TR based reconstruction of ENH temperatures that extends (with reasonable chronology replication) to 2000 and shows not only increasing reconstructed temperatures in general agreement with the instrumental data but also indicates that the late 1990s have been the warmest period for the last 250 years. Despite the improvement of WNH2007 compared to previous NH reconstructions, some discussion is needed to try and address why there is still underestimation of predicted values in the recent period:

\subsection{Issues Related to the Instrumental Predictand Data}

\subsubsection{Urban Heat Island Effect}

[18] The Urban Heat Island (UHI) effect is another source of uncertainty in the recent period that could bias recent instrumental temperatures upward. However, with a quantified large-scale influence of $0.0055^{\circ} \mathrm{C} /$ decade [Folland et al., 2001; Brohan et al., 2006], this effect, as often cited [e.g., Intergovernmental Panel on Climate Change, 2001, 2007], has only a minimal effect upon hemispheric temperatures and therefore has only a small potential influence upon the divergence problem for ENH reconstructions. The

Table 3. Correlation Matrix (1750-1992) Between WNH2007 and Previous TR Based Reconstructions of ENH Temperatures

\begin{tabular}{lcccc}
\hline & DWJ2006STD & DWJ2006RCS & ECS2002 & BRF2000 \\
\hline WNH2007 & 0.79 & 0.77 & 0.75 & 0.75 \\
DWJ2006STD & & 0.92 & 0.80 & 0.87 \\
DWJ2006RCS & & & 0.88 & 0.89 \\
ECS2002 & & & & 0.82 \\
\hline
\end{tabular}


Table 4. Correlations Between WNH2007 and ENH Instrumental Temperatures $^{\mathrm{a}}$

\begin{tabular}{lcc}
\hline & Annual & Summer \\
\hline $1850-1988$ & 0.50 & 0.35 \\
$1850-2000$ & 0.59 & 0.48 \\
$1880-1988$ & 0.55 & 0.60 \\
$1880-2000$ & 0.62 & 0.66 \\
\hline
\end{tabular}

${ }^{\mathrm{a}}$ The summer season is May-August.

UHI effect, however, could be more relevant for local TR based studies that show divergence.

\subsubsection{Early Instrumental Record}

[19] The robustness of the ENH instrumental record decreases going back in time as the number of constituent station data decrease [Brohan et al., 2006]. It has been suggested for studies in Europe [Moberg et al., 2003; Büntgen et al., 2005, 2006b; Frank and Esper, 2005], coastal Alaska [Wilson et al., 2007] and for the Northern Hemisphere [Esper et al., 2005; D. C. Frank et al., Warmer early instrumental measurements versus colder reconstructed temperatures: Hemispheric to regional evidence, submitted to Quaternary Science Reviews, 2007, hereinafter referred to as Frank et al., submitted manuscript, 2007] that instrumental temperatures in the 19th century are possibly "too warm" because of homogenization correction procedures. If this is the case, inclusion of earlier instrumental data may bias reconstructed values. Using the WNH2007 series, calibrations using annual temperatures made over the 1850-1988 and 1880-1988 periods result in respective correlations of 0.50 and 0.55 (Table 4) with resultant little difference in the overall trend/amplitude of the final time series. The slight improvement in calibration using the shorter period is not statistically significant. However, this difference becomes arguably more significant when summer temperatures are the target seasonalized parameter, which has important repercussions for large-scale TR based reconstructions (see next section).

\subsubsection{Target Season}

[20] Most reconstructions of $\mathrm{NH}$ temperatures calibrate against an annualized (e.g., January-December) parameter despite the fact that many of the constituent proxy series may be best quantified as summer temperature series at the local/regional scale (Table 1 and Figure 3). It has, however, been argued that trees from selected tree line sites may integrate climate conditions during non-growing-season months [e.g., Jacoby and D'Arrigo, 1989; Payette et al., 1996; Frank and Esper, 2005] and therefore better calibration may be obtained, over large hemispheric scales, against annualized temperatures rather than the summer season. The WNH2007 series appears initially to be no different in this regard. Over the 1850-1988 period, the correlation of this series to annual and summer (May-August) ENH temperatures is 0.50 and 0.35 respectively (Table 4). This weakening in coherence for the summer season is likely related to the proxy data not being able to model well the relatively warmer 19th century temperatures expressed in the instrumental summer ENH data (see Figure 5a and also Esper et al. [2005] and Frank et al. (submitted manuscript, 2007) for a more detailed discussion). If, however, calibration is made over the shorter period, $1880-1988$, the WNH2007 series correlates with annual and summer (May-August) ENH temperatures at 0.55 and 0.60 (Table 4). Despite there being no statistical difference between these two correlation values, this result, along with those of the previous section, therefore lead to a simple choice when reconstructing largescale ENH temperatures: should a data set of proxy series that are generally weighted to the summer season (but which may integrate conditions throughout the year), be used to model annual temperatures at large scales, or should TR based summer-weighted proxies be used exclusively to reconstruct large-scale summer temperatures, but with calibration excluding the early period where possibly instrumental temperatures are "too warm"?

\subsubsection{Target Temperature Parameter}

[21] Wilson and Luckman [2003] hypothesized that when trees grow in temperature-limited environments, in regions where there is a significant difference in trend between daytime maximum and nighttime minimum temperatures, they will show greatest response to maximum temperatures since the bulk of cambial activity (i.e., photosynthesis and respiration) occurs during the daytime. Although this

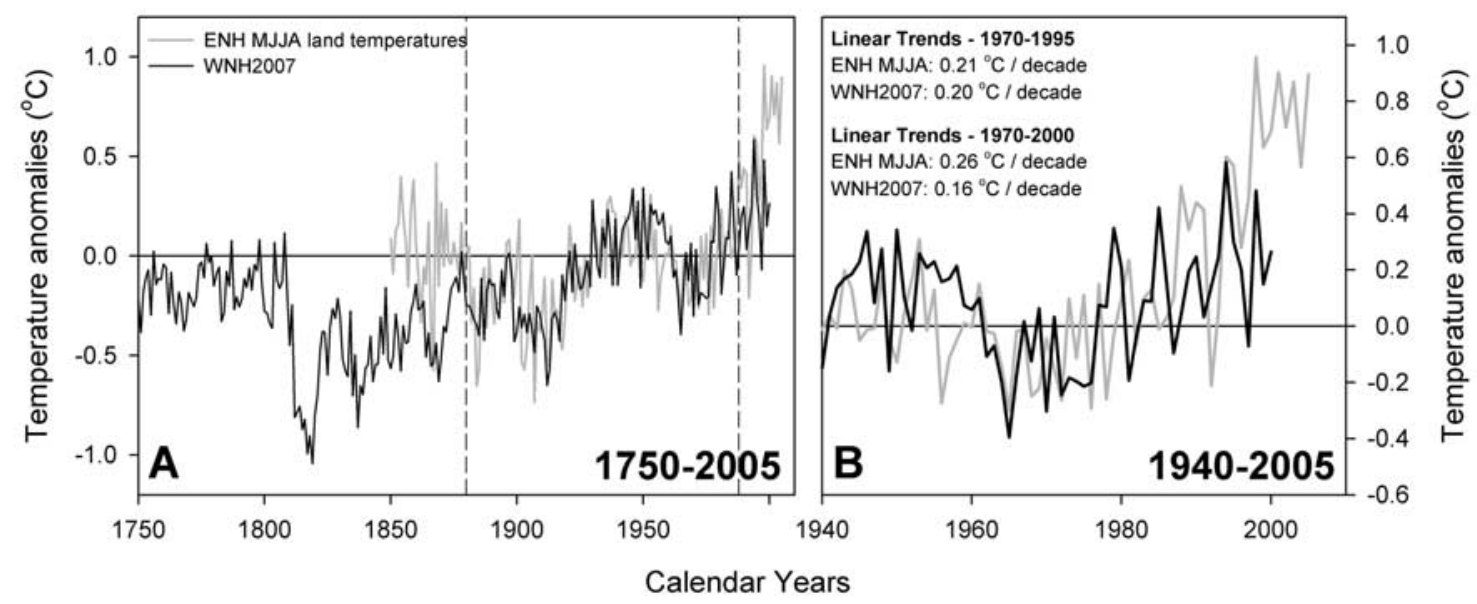

Figure 5. Calibration (1880-1988) of WNH2007 against summer May-August $\left(20-90^{\circ} \mathrm{N}\right)$ ENH land temperatures. 


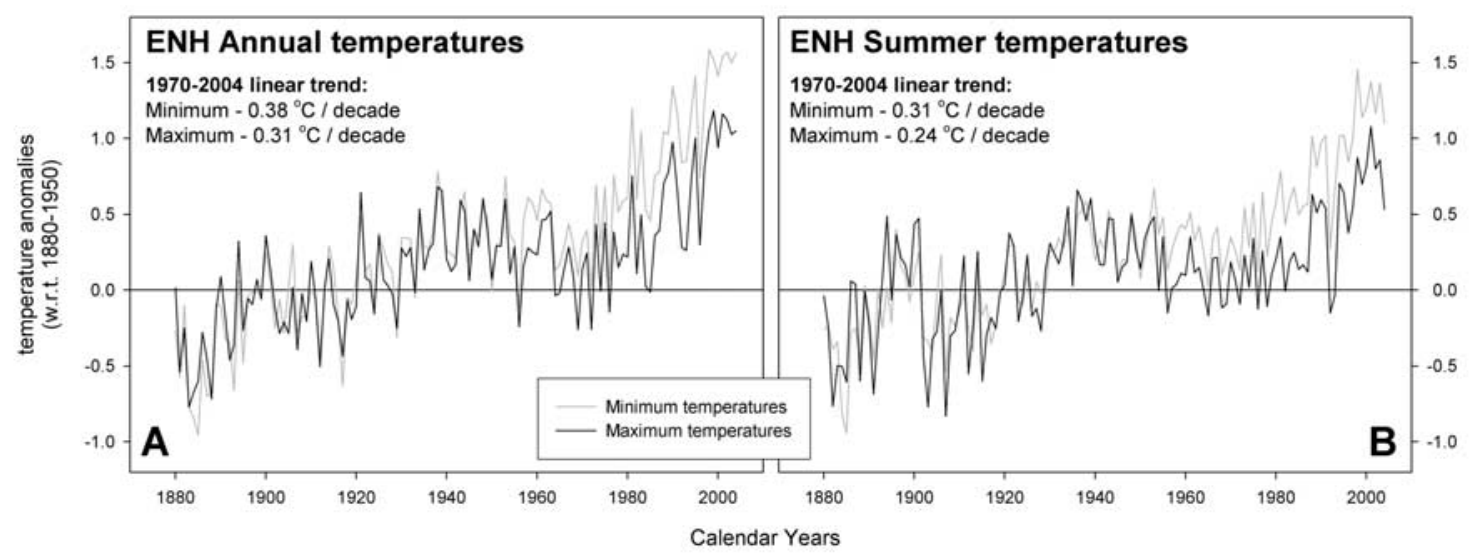

Figure 6. Comparison between minimum and maximum ENH $\left(20-90^{\circ} \mathrm{N}\right)$ temperatures for the (a) annual and (b) summer seasons. Note the data have been transformed to anomalies with respect to the 1880-1950 period to highlight the difference in the recent period. The instrumental data and their sources are detailed by Vose et al. [2005].

hypothesis is essentially untested, Youngblut and Luckman [2007] showed that superior calibrations were obtained against maximum temperatures in the southern Yukon (see auxiliary material). Similar calibration results are also reported utilizing a composite tree ring maximum density chronology for the central Spanish Pyrenees (U. Büntgen et al., Eight centuries of Pyrenees summer temperatures from tree-ring density, submitted to Climate Dynamics, 2007, hereinafter referred to as Büntgen et al., submitted manuscript, 2007) where a significant trend difference between maximum and minimum temperatures exists. Frank et al. [2007] have also documented a stronger response with maximum temperatures from trees in the Central Altay mountains in Russia. At hemispheric scales, studies of 20th/21st century instrumental climate records [Karl et al., 1993; Easterling et al., 1997; Vose et al., 2005] have shown that minimum temperatures have been rising significantly faster than mean or maximum temperatures. Vose et al. [2005] show that over the 1950-2004 period, the increasing linear trend of $\mathrm{NH}$ annual maximum temperatures is $0.15^{\circ} \mathrm{C} /$ decade, while minimum temperatures have increased by $0.23^{\circ} \mathrm{C} /$ decade. Focusing on the recent period, Figure 6 further highlights the greater linear increase of minimum temperatures since 1970 compared to maximum temperature for both the annual $\left(0.38^{\circ} \mathrm{C}\right.$ versus $0.31^{\circ} \mathrm{C} /$ decade $)$ and summer $\left(0.31^{\circ} \mathrm{C}\right.$ versus $0.24^{\circ} \mathrm{C} /$ decade $)$ seasons. If indeed trees do respond predominantly to daytime maximum temperatures, then the difference in trend between maximum and minimum temperatures at hemispheric scales may be a further factor that needs to be taken into account when calibrating against large-scale temperatures. However, the results from calibration trials using both ENH minimum and maximum temperatures are ambiguous. Figure 7 compares WNH2007 against ENH maximum and minimum temperatures for the annual and summer seasons after scaling over the 1880-1988 period. The highest correlation $(r=0.63)$ is found against ENH summer minimum temperatures. However, WNH2007 clearly does not track recent summer minimum temperatures well after 1988 (Figure 7d) with results generally similar to the standard approach of calibrating against mean temperatures (Figures 4 and 5). Scaling WNH2007 against summer ENH maximum temperatures (Figure 7b), however, despite the correlation being weaker $(\mathrm{r}=0.53)$, results in the proxy reconstruction actually expressing a slightly greater increasing trend $\left(0.23^{\circ} \mathrm{C}\right.$ versus $0.21^{\circ} \mathrm{C} /$ decade $)$ over the 1970 2000 period compared to the instrumental data.

\subsection{Issues Related to the Number of Proxy Records}

\subsubsection{Proxy Replication}

[22] D'Arrigo et al. [2006] argued that because of the low number of temperature sensitive chronologies existing for the pre-1400 period in their ENH reconstruction, the temperature estimates for this earlier period (i.e., the Medieval Warm Period) must be interpreted cautiously. This observation was emphasized in the recent $N R C$ [2006, p. 110] report where they stated that current "large-scale temperature reconstructions should always be viewed as having a 'murky' early period." In this study, the same can be said for the recent period (i.e., it gets "murkier" as we extend beyond 1988). The successful reconstruction of ENH temperatures, therefore, must use a sufficiently replicated network of proxies. Despite the encouraging verification results, the quality of the WNH2007 reconstruction weakens as the number of proxy series decreases toward 2000 (Table 2). Is it possible, therefore, that some of the noted post-1988 divergence is simply related to the low number of proxy records used? To test this, we utilized the optimal seasonal (mostly summer) instrumental series used to calibrate the 15 TR proxy series (Table 1 and Figure 3), to derive an instrumental based reconstruction of ENH temperatures. Because of the varying length of the local/regional instrumental series, a nesting procedure as used for WNH2007 was not used. Rather, the series were normalized to their common period (1942-1995), averaged for each continent, and a final $\mathrm{NH}$ mean series derived by averaging the continental series together (again after renormalizing these series to 1942-1995). The variance of the continental 
ENH Annual temperatures
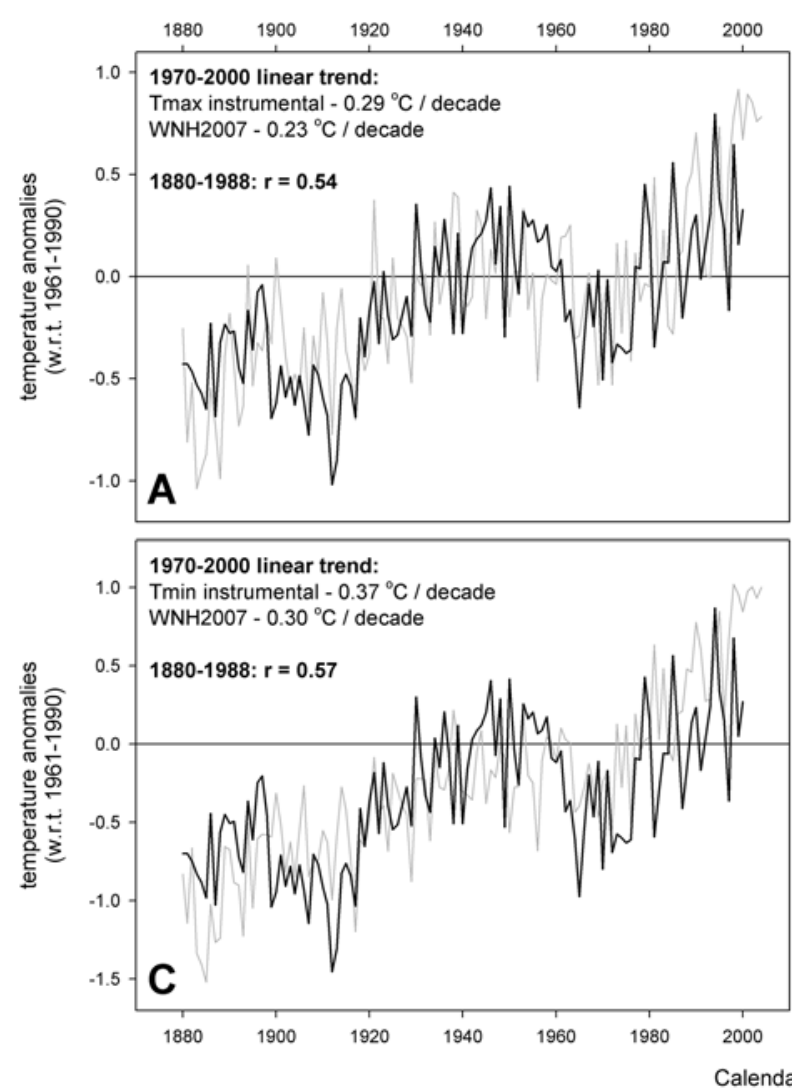

ENH Summer temperatures

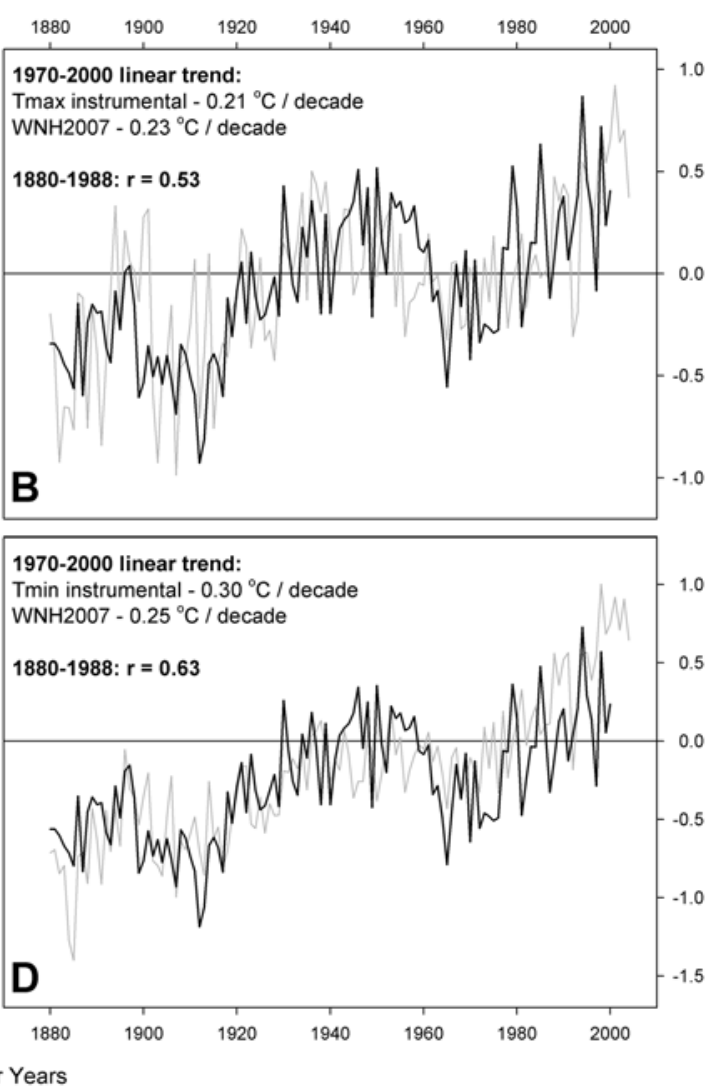

Figure 7. WNH2007 scaled (1880-1988, black line) to ENH (a and b) maximum and (c and d) minimum temperatures for the annual (Figures $7 \mathrm{a}$ and $7 \mathrm{c}$ ) and summer (Figures $7 \mathrm{~b}$ and $7 \mathrm{~d}$ ) seasons. Instrumental data are in grey, while WNH2007 is black.

mean series was stabilized using the Osborn et al. [1997] method. This instrumental based reconstruction (hereafter INSTNH) was calibrated (scaled) to both annual and summer ENH mean temperatures over the 1889-1988 period (the inner year denotes the point at which replication was at least two instrumental series per continent). Figure 8 presents the calibration results and shows a weaker correlation with annual ENH temperatures $(r=0.47$, Figure 8a) compared to the summer season $(r=0.60$, Figure $8 b)$. As the predominant season of the local grid temperature series is weighted to summer, the higher correlations with ENH summer temperatures (Figure 8b) are perhaps not surprising. However, for both annual and summer ENH temperatures, a slight divergence is observed after 1988. The linear trends (1970-2000) of the actual and reconstructed ENH series for the annual $\left(0.32^{\circ} \mathrm{C}\right.$ versus $0.19^{\circ} \mathrm{C} /$ decade) and summer $\left(0.26^{\circ} \mathrm{C}\right.$ versus $0.17^{\circ} \mathrm{C} /$ decade $)$ seasons clearly suggests that from using such a sparse network of time series it is not possible to model recent warming well.

4.2.2. Spatial Sampling of Proxy Series and Their Coherence to ENH Temperatures

[23] On the whole the above analyses suggest that (1) summer ENH temperatures may possibly be the optimal target parameter (although further work is needed to address both the quality of the pre-1880 instrumental data and the physiological relationship of tree growth to summer and annual temperatures) and (2) the post-1988 divergence might also simply be a product of low replication. To possibly exacerbate the problem of low replication, the balance of those proxies that correlate positively with $\mathrm{NH}$ temperatures versus those that do not may also bias the final mean function as well. As stated earlier, two of the TR proxies (TAT and TSH) show slight decreasing trends through the 20th century and so correlate inversely with ENH temperatures (Table 1). NEP and IDA also correlate weakly with ENH temperatures. It is possible, therefore, that the inclusion of these proxy series may slightly bias the final WNH2007 series downward in the recent period. If these series are excluded when generating WNH2007, the final hemispheric time series is very similar $(r=0.95)$ to the full data set version (Figure 9). However, over the 19702000 period, the linear trend is actually marginally greater $\left(0.17^{\circ} \mathrm{C}\right.$ versus $0.11^{\circ} \mathrm{C} /$ decade $)$ in the original WNH2007 series suggesting that the removal of these four series weakens the overall ENH reconstruction. These results are ambiguous, but essentially highlight the sensitivity of the removal of a few series on the final mean function when replication is generally low. Therefore one interpretation is that TR proxy series that correlate negatively or weakly 


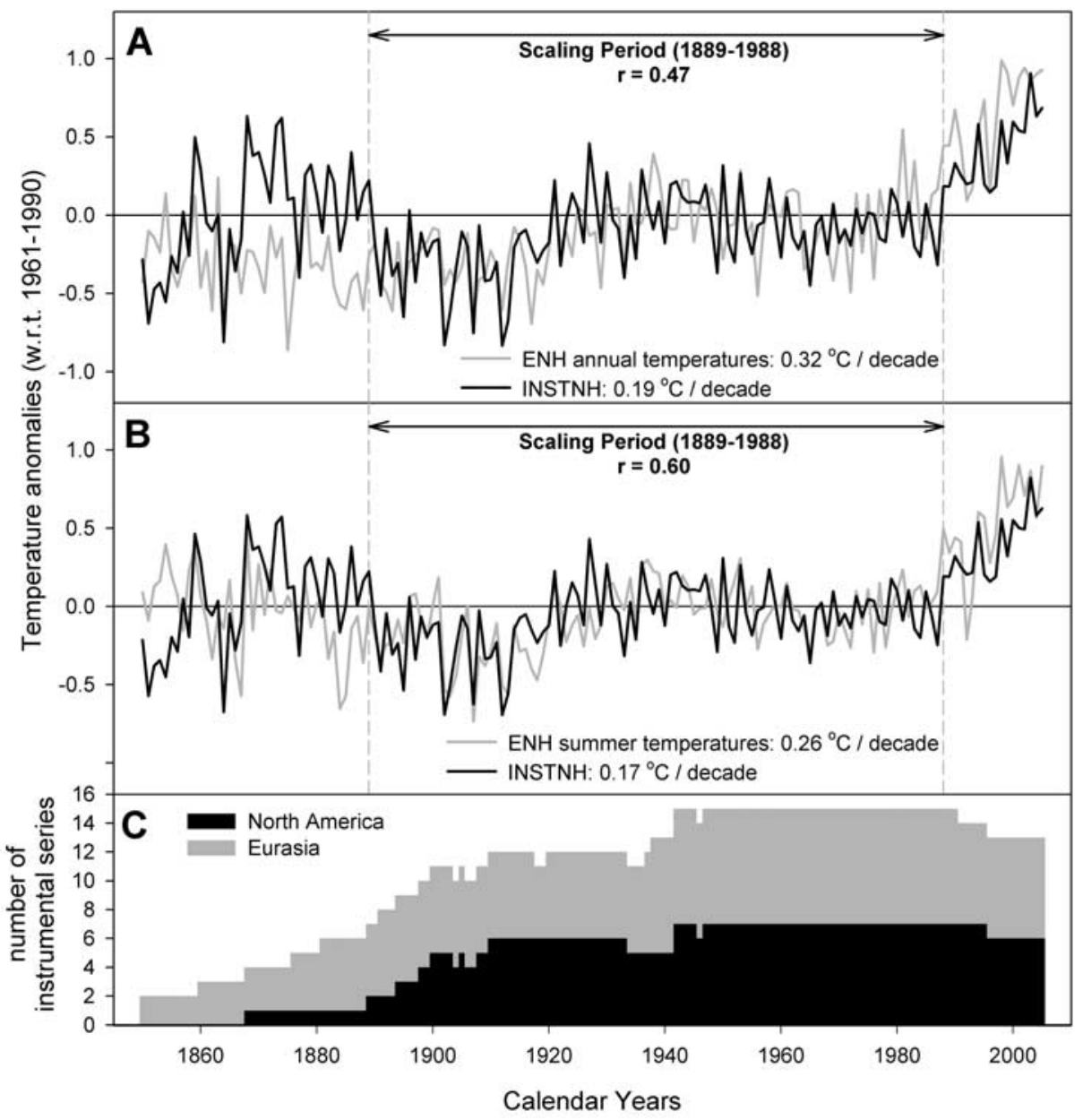

Figure 8. Instrumental based reconstruction of (a) annual and (b) summer ENH temperatures using the local gridded temperature series used for calibration of the individual proxy records. Calibration (scaling) was undertaken over the 1889-1988 period. The early year denotes the point at which at least two instrumental series exist for each continental mass. (c) Replication of instrumental records through time.

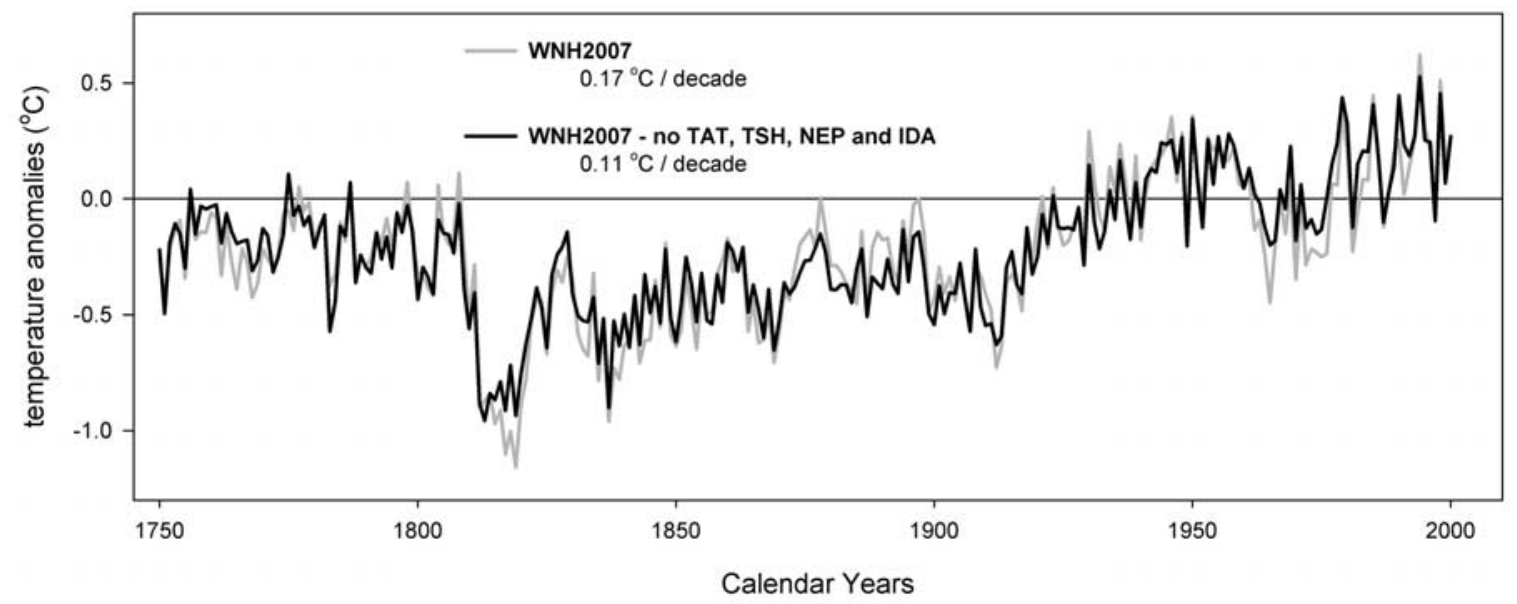

Figure 9. WNH2007 reconstruction compared with a similar reconstruction that was developed without using TAT, TSH, NEP and IDA. Both series have been scaled (1850-1988) to extratropical instrumental $\left(20-90^{\circ} \mathrm{N}\right) \mathrm{NH}$ annual land temperatures. Decadal trends are calculated over the $1970-2000$ period. 
with ENH temperatures, so long as they are robust representations of their local temperature records should not necessarily be excluded from NH reconstructions. However, considerable caution is required. For example, it would not be possible to develop a robust large-scale reconstruction of $\mathrm{NH}$ temperatures using a network of local/regional proxies, despite being robust estimates of local temperatures, that were all inversely correlated or weakly correlated with large-scale temperatures. Therefore a careful balance of sites, representing the actual balance shown in the instrumental record, is needed.

\section{Conclusion}

[24] Utilizing a data set of TR based published local/ regional reconstructions and new TR chronologies, we have developed a new and completely independent reconstruction of ENH temperatures (WNH2007, 1750-2000) that compares well with previous reconstructions up to the mid1980s. The constituent TR proxy time series were chosen as they portrayed relatively robust estimates of local/regional temperatures, showed no divergence in the recent period with their respective instrumental predictand records and allowed reasonable replication up to 2000 in the final reconstructed time series. We hypothesized that the utilization of TR based proxies that show no divergence at the local-scale could result in better estimates of hemispheric temperatures in the recent (post-mid-1980s) period where all other TR based ENH hemisphere reconstructions [Briffa, 2000; Esper et al., 2002; D'Arrigo et al., 2006] diverge below the increasing trends in the instrumental data. The WNH2007 reconstruction does indeed portray a significant increase in predicted values for the last two decades, with the warmest decade over the last 250 years being 19891998 , although there is still some underestimation in the predicted values compared to measured values over this period.

[25] This study shows that TR data can better model recent warming at large scales when constituent chronologies are chosen that show no divergence at the local scale. To conclude, while recognizing that there are also debates over methodological approaches [Bürger et al., 2006; Esper et al., 2005; McIntyre and McKitrick, 2005; Mann et al., 2005; Rutherford et al., 2005; von Storch et al., 2004, 2006] and the utilization of other proxy types [Jones et al., 1998; Mann et al., 1998; Moberg et al., 2005; Hegerl et al., 2007] that need to be resolved, we list recommendations [see also $N R C, 2006]$, with regards to proxy and instrumental data, that should be taken into account for future attempts of reconstructing large-scale temperatures:

[26] 1. Only TR data that express a robust nonbiased estimate of local/regional temperatures should be used. The degree of coherence of a particular record with NH temperatures, so long as it correlates robustly with local temperatures, is only of minimal importance so long as proxy replication is high.

[27] 2. The "divergence problem" needs to be addressed and explored at the local/regional scale. For those TR records where the divergence effect can be attributed to anthropogenic influences (i.e., related to pollution or dimming etc.) the data can be truncated at the point where divergence starts, and the rest of the data used [see Wilson and Elling, 2004]. Alternatively if these effects are seen to be the result of detrending "end effects" [Melvin, 2004; K. Briffa and T. Melvin, Climatic Research Unit, personal communication, 2006], correction can be made using improved detrending techniques. With respect to temporally unstable relationships, palaeoclimatology must ultimately rely on James Hutton's principle of uniformitarianism whereby relationships between proxies and their targets, drawn during the calibration interval, are assumed to remain relatively stable over time. Therefore, for those TR chronologies which express a significant response change with climate (e.g., a weakening in temperature response due to an increase in moisture stress), these series should be used with caution (or in some cases not at all) for such large-scale reconstructions of past temperatures since it is not possible to quantify whether such nonlinear response changes have also occurred in the past, unless it is presumed that such a nonlinear response is unique to the recent anthropogenic period.

[28] 3. Currently, most NH temperature reconstructions target the annual season despite the individual proxies generally portraying a summer signal at local scales. Although it has been argued that trees from selected tree line sites may integrate climate conditions during non-growingseason months [Jacoby and D'Arrigo, 1989; Payette et al., 1996; Frank and Esper, 2005], this tendency may also be partly related to a better empirical "fit" between the proxy and instrumental annual data prior to 1880 , a period where the quality of large-scale hemispheric instrumental data can be questioned. Calibration trials using WNH2007 against ENH temperatures (Figure 5 and Table 4), excluding the pre-1880 period, show similar results for both the annual and summer seasons. Therefore more detailed explorative work assessing the quality of instrumental series prior to the $1880 \mathrm{~s}$ is needed before a balanced decision can be made on which is the optimal target seasonal parameter for reconstruction. Further calibration trials (Figure 8), but utilizing a mean of the gridded temperature series used for calibration of the individual TR proxy series, strongly suggest that ENH summer temperatures would be the optimal large-scale target instrumental predictand season.

[29] 4. The research of Wilson and Luckman [2003], and the simple analyses made in this study suggest that optimal calibration, with regards to tracking recent temperature trends using TR data, can be gained by targeting maximum rather than mean temperatures. To test this hypothesis, however, more explorative work on tree ring growth/ temperature relationships is needed in regions where there is a significant difference in trend between nighttime and daytime temperatures [e.g., Youngblut and Luckman, 2007; Büntgen et al., submitted manuscript, 2007]. If indeed a predominant optimal tree response is found with maximum temperatures at temperature limiting locations (i.e., altitudinal and latitudinal tree lines), this would have major implications for dendroclimatology that must be addressed in the ongoing discussion of late 20th/early 21 st-century changes in tree ring/climate relationships.

[30] 5. Finally, not only are much more data needed in the early pre-1400 period [Cook et al., 2004; NRC, 2006; D'Arrigo et al., 2006] to increase replication and therefore improve large-scale reconstruction confidence during these earlier periods, but existing data sets also need to be updated 
to present, as well as incorporating new data sets, to allow more robust comparison with the instrumental record over recent decades.

\section{Appendix A: Description of the 15 TR Proxy Records}

\section{A1. European Alps}

[31] Two summer temperature reconstructions have recently been developed for the Alpine region. Büntgen et al. [2005], using 1,527 ring width (RW) measurements from living trees and relict wood, produced a June-August temperature reconstruction back to AD 951. The reconstruction is composed of larch data (Larix decidua) from four Alpine valleys in Switzerland and pine data (Pinus cembra) from the western Austrian Alps. These regions are situated in high-elevation Alpine environments where a spatially homogenous summer temperature signal exists. The regional curve standardization technique (RCS [Mitchell, 1967; Briffa et al., 1992; Cook et al., 1995; Esper et al., 2003a]) was applied to the RW measurements in an attempt to capture the full frequency range of summer temperatures over the past millennium. In a related study, Büntgen et al. [2006b], utilized maximum density (MXD) data (processed using RCS) from 180 recent and historic high-elevation tree ring (TR) series from the Swiss Alps to develop a summer temperature reconstruction over the AD 755-2004 period. This reconstruction correlates at $\sim 0.7$ with Alpine highelevation summer temperatures back to 1818. Both Alpine records suggest that summer temperatures during the last decade are unprecedented over the past millennium. Over the 951-2002 common period, both reconstructions correlate at 0.55 and therefore, for this study, were averaged together after they had been normalized to their common period. The resulting mean time series correlates with gridded $\left(45-50^{\circ} \mathrm{N} / 5-10^{\circ} \mathrm{E}\right)$ temperatures (May-September) at 0.64 , and shows no autocorrelation in the model residuals (Table 1). Some of the pine data used by Büntgen et al. [2005] was included in the generation of the D'Arrigo et al. [2006] RCS NH reconstruction. These data were not included in their STD version however.

\section{A2. Tatra Mountains}

[32] From a network of $24 \mathrm{RW}$ and four MXD chronologies Büntgen et al. [2007] developed two summer temperature reconstructions for the Tatra region in Poland and Slovakia. The trees in the network consisted of four conifer species (Picea abies, Larix decidua, Abies alba, and Pinus mugo) from which ring width and maximum density measurements were standardized using individual series detrending approaches. Principal component analysis identified five dominant eigenvectors that express somewhat contrasting climatic signals. The first principal component contains highest loadings from 12 Picea abies RW chronologies and explains $42 \%$ of the network's variance. The mean of these 12 high-elevation chronologies correlates at 0.62 with June-July temperatures, while the mean of the three MXD chronologies that load most strongly on the fourth principal component, correlates at 0.69 with April-September temperatures. These groupings allowed the development of RW and MXD based reconstructions of June-July (1661-2004) and April-September (1709-2004) temperatures, respectively. For this study, we utilized the broader seasonal windowed MXD based reconstruction (correlates with local April-September gridded temperatures at 0.67, Table 1) as the RW based temperature proxy showed significant autocorrelation in the model residuals when it was regressed against the gridded data.

\section{A3. Northern Scandinavia}

[33] Kirchhefer [2001] developed July-August temperature reconstructions using RW data (each TR series detrended individually) from Scots pine (Pinus sylvestris) for three regions in Norway: Forfjorddalen in the Vesterålen archipelago (AD 1358-1992), Stonglandseidet on Senja (AD 1548-1994) and Vikran near Tromsø (AD 17001992). The correlations of these reconstructions with local station data were $0.56,0.50$ and 0.71 respectively. As detailed by Kirchhefer [2001, Figure 6], these three series were combined to develop a regionally representative temperature proxy time series (1700-1989). For this study, we "extended" the Kirchhefer [2001] study to 2001 by complimenting the original chronology data with new recently archived RW chronologies from Norway and Finland. The old and new data were obtained from the International Tree ring Data-Bank (ITRDB) (http://www.ncdc.noaa.gov/paleo/ treering.html). Only chronologies that correlated significantly with July-August gridded temperatures $\left(65-70^{\circ} \mathrm{N} / 15-\right.$ $30^{\circ} \mathrm{E}$ ) were considered for further analysis. The chronologies (with ITRDB code, latitude/longitude, and period with $>10$ series) that passed this screening were (1) Tutkimusasema (FINL054, $\left.67^{\circ} \mathrm{N} / 26^{\circ} \mathrm{E}, 1586-2000\right)$, Vytamoselka (FINL055, $67^{\circ} \mathrm{N} / 27^{\circ} \mathrm{E}, 1577-2001$ ), Rorstaddalen (NORW011, $67^{\circ} \mathrm{N} / 15^{\circ} \mathrm{E}, 1550-1997$ ) and Borealoa River (NORW012, $67^{\circ} \mathrm{N} / 15^{\circ} \mathrm{E}$ ) [Melvin, 2004], and(2)Karhunpesäkivi Inari (FINL021, $\left.\left.68^{\circ} \mathrm{N} / 27^{\circ} \mathrm{E}, 1509-2001\right), 1625-1997\right)$ and Karasjok (NORW007, $69^{\circ} \mathrm{N} / 25^{\circ} \mathrm{E}, 1733-2001$ ) (updated sites from Lindholm et al. [1996]); Stonglandseidet (NORW009, $69^{\circ} \mathrm{N} / 17^{\circ} \mathrm{E}, 1537-1997$ ) and Forfjorddalen 2 (NORW010, $\left.68^{\circ} \mathrm{N} / 15^{\circ} \mathrm{E}, 1254-1993\right)$ [Kirchhefer, 2001]. Note that the Forfjorddalen 2 chronology was included despite its termination in 1993 as it was utilized in the original Kirchhefer [2001] study. These chronologies were detrended using so-called standard techniques (either negative exponential or regression functions of negative or zero slope). The resultant chronologies were normalized over their common period (1733-1993), averaged to derive a regional mean series and the variance of the time series stabilized using the method outlined by Osborn et al. [1997]. This final mean series (1733-2000) correlates with July-August temperatures at 0.61 (Table 1) and coheres strongly $(\mathrm{r}=0.75)$ with the original Kirchhefer [2001] regional series (see Figure A1).

\section{A4. Western Siberia}

[34] Both RW and MXD parameters were measured (at the Swiss Federal Institute for Forest, Snow and Landscape Research) from a newly sampled larch (Larix sibirica) site in western Siberia (Putorama, $70^{\circ} 31^{\prime} \mathrm{N} / 92^{\circ} 57^{\prime} \mathrm{E}$ ). The period where replication is at least 10 series is $1713-2000$. The two data types were detrended using standard individual series methodologies and mean chronologies computed. As both chronologies correlated reasonably strongly with each other $(\mathrm{r}=0.61)$ and their response to summer temperatures 


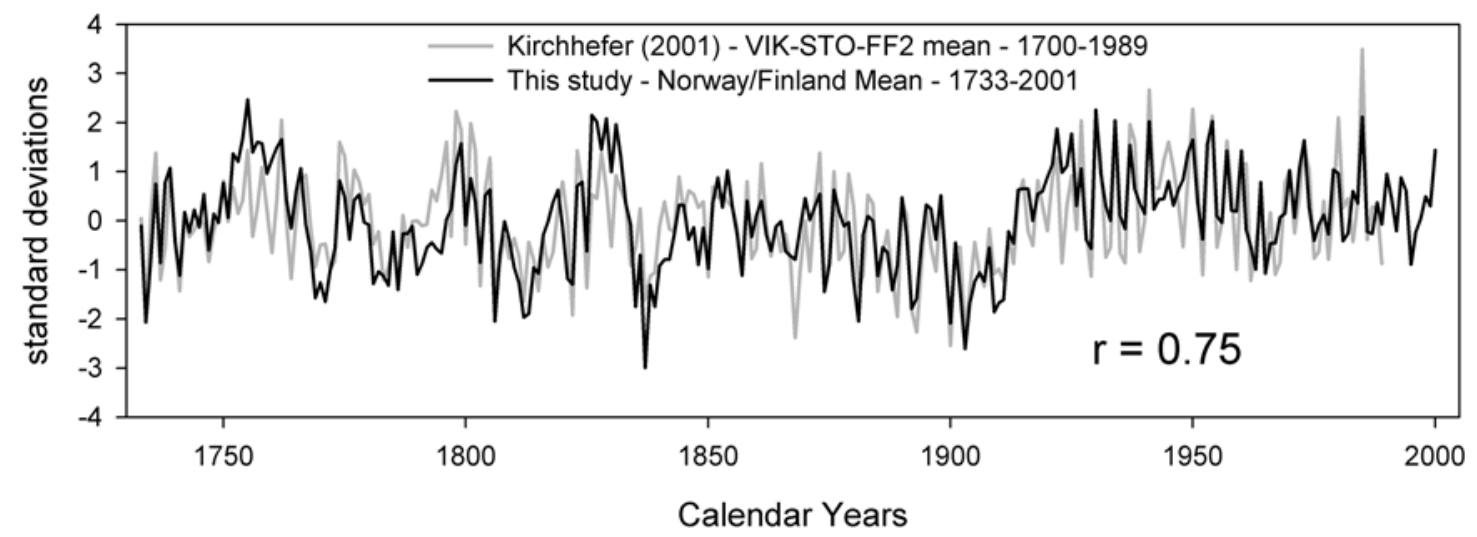

Figure A1. Comparison of the original Kirchhefer [2001] reconstruction with the updated version (SCA) developed in this study.

was similar, they were averaged together, after being normalized to the common period, to derived a mean summer temperature proxy for the region. This series correlates with mean May-September gridded temperatures at 0.43 (Table 1). The Western Siberia series tracks the gridded temperature series quite well (Figure 3) except for the last two years, where the proxy values are substantially lower than the actual instrumental data. These two years of misfitting are too short to identify whether this is a significant divergence.

\section{A5. Mongolia}

[35] This record was derived from combining two temperature-sensitive elevational tree line RW records from Mongolia-Khalzan Khamar (Larix sibirica; ITRDB code: MONG009, $49.55^{\circ} \mathrm{N} / 91.34^{\circ} \mathrm{E}$ ) and Horin Bugatyin Davaa (Pinus sibirica; MONG009, $49.22^{\circ} \mathrm{N} / 94.53^{\circ} \mathrm{E}$ ). These two series were chosen from data presented by $D^{\prime}$ Arrigo et al. [2000] as they expressed the strongest response to summer temperatures. The chronologies were detrended using standard methods, and after normalizing to the common period, averaged to derive a mean series. The period replicated with $>10$ series is $1636-1998$. This composite record is independent of the Solongotyin Davaa record used in D'Arrigo et al. [2006] and correlates well $(\mathrm{r}=0.70)$ with gridded June-July temperatures (Table 1).

\section{A6. Kyrgyzstan}

[36] A search through the ITRDB, found surprisingly few temperature sensitive TR data sets that came up to at least 1995. Kyrgyzstan was one region where such chronologies were found (sampled and measured by the Swiss Federal Institute for Forest, Snow and Landscape Research). In this region, both RW and MXD data were obtained from two spruce (Picea shrenkiana) sites Sarejmek (ITRDB code: RUSS152, $41.36^{\circ} \mathrm{N} / 75.09^{\circ} \mathrm{E}$ ) and Tschongkys (RUSS164, $\left.42.11^{\circ} \mathrm{N} / 78.11^{\circ} \mathrm{E}\right)$. Chronologies were computed using standard techniques. The period covered by at least 10 series in each chronology is 1689-1995. To account for the varying coherence between each chronology, the chronologies were not averaged to derive site mean series, but rather the RW and MXD chronologies were utilized separately as potential predictor series in a stepwise multiple regression against gridded temperatures. The final optimal model was calibrated against June-July mean temperatures, with the final series being a linearly weighted combination of the Sarejmek MXD and RW data as well as the RW data from Tschongkys. The final Kirgistan reconstruction explains $36 \%(r=0.61$. Table 1) of the gridded temperature variance.

\section{A7. Tien Shan}

[37] Esper et al. [2003b] developed a chronology from 203 Juniperus turkestanica RW series to reconstruct temperature variations in the Tien Shan Mountains (Kirghizia). The Tien Shan RW data were detrended to remove tree age related biases and to emphasize high- to low-frequency climatic signals over the past millennium. Esper et al. [2003b] showed that the data correlated most strongly with the June-September temperatures of the Fergana meteorological station in eastern Uzbekistan $(r=0.46)$. In this study, taking into account residual analysis, we identified the optimal correlation $(\mathrm{r}=0.41)$ with July gridded temperatures (Table 1).

\section{A8. Nepal}

[38] Cook et al. [2003] described the development of a multispecies (Abies spectabilus, Juniperus recurva, Populus ciliata, Pinus roxburghii, Picea smithiana, Pinus wallichiana, Tsuga dumosa and Ulmnus wallichiana) TR chronology network in Nepal and the development of two temperature reconstructions. The network was composed of 32 TR chronologies (processed using the RCS method) and was represented by five indigenous tree species. Principal component analysis of the chronologies over the common interval 1796-1792 indicated that there was a coherent large-scale common signal among the TR chronologies which was hypothesized to reflect, in part, broad-scale climate forcing related to temperatures. Using monthly temperature data from Kathmandu two reconstructions were developed: February-June (1546-1991) and OctoberFebruary (1605-1991). In this study, we utilize the February-June reconstruction as it incorporates the summer season (to be consistent with the other TR proxies). We found the optimal season of coherence to be with MarchMay temperatures $(\mathrm{r}=0.49)$. 


\section{A9. Colorado}

[39] Using Pinus aristata RW data (detrended using standard techniques) from the San Francisco Peaks in Arizona, Salzer and Kipfmueller [2005] developed $>2000$ year long reconstruction of annual temperatures for the region. In the original study, the reconstruction explains $46 \%$ of the variance in the temperature data over the 1909 1994 calibration period. In this study, correlations with gridded temperatures were not so strong $(0.42,1889-$ 1996), but still passed the screening criteria.

\section{A10. Idaho}

[40] Biondi et al. [1999], using RW data (detrended using standard techniques) from whitebark pines (Pinus albicaulis) and Douglas firs (Pseudotsuga menziesii), developed an 858-year proxy records of July temperatures for east-central Idaho. The correlation of their proxy series with instrumental July temperatures was $0.47(1895-1992)$ with this improving to 0.55 when the $1895-1903$ period was removed. In this study, using gridded data from a relatively large region $\left(40-45^{\circ} \mathrm{N} / 110-120^{\circ} \mathrm{W}\right)$, we show that these correlations are generally consistent back into the 19 th century $(\mathrm{r}=0.41,1868-1992)$.

\section{A11. British Columbia}

[41] Wilson and Luckman [2002] demonstrated the possibility of reconstructing both May-August maximum (Tmax) and minimum (Tmin) temperatures using RW and MXD series (detrended using standard techniques) from (Engelmann spruce (Picea engelmannii Parry) at tree line sites across Interior British Columbia, Canada. Multiple linear regression of three orthogonal principal components (derived from $12 \mathrm{RW}$ and 7 MXD chronologies) were used to reconstruct each climate parameter separately. Calibration explained 64\% (Tmax) and 39\% (Tmin) of the variance in the instrumental climate record (1895-1991). In this study, we utilize the same data set as Wilson and Luckman [2002], except we removed the Harts Pass (Washington State) RW chronology (1585-1991) from the data set. The chronologies were used over the period denoted by at least 10 series (1750-1997) and principal component analysis identified three principal component scores comparable to those of the original study. Using stepwise multiple regression, calibration against mean May-August gridded temperatures (1894-1997) resulted in a reconstruction explaining 58\% of the temperature variance $(r=0.77$, Table 1$)$. The reconstruction code (Table 1) is denoted by MBC to minimize confusion with the IBC maximum temperature reconstruction detailed by Wilson and Luckman [2003].

\section{A12. Southern Yukon}

[42] Youngblut and Luckman [2007] utilized a network of high-elevation Picea glauca TR chronologies from the southwest Yukon to reconstruct June-July maximum temperatures back to $1684 \mathrm{AD}$. The chronologies (processed using standard methods) are characterized by low interannual RW variability and display similar patterns of RW variability across the sample area over the last 300 years. The driving force of this common signal appears to be a common tree growth response to summer temperatures across the region. Using seven chronologies a reconstruction of maximum June-July temperatures was developed back to 1684 A.D., explaining $46.6 \%$ of the climatic variance over the 1946-1995 calibration period. In this study, we correlate this record with gridded temperature from a broader region $\left(60-65^{\circ} \mathrm{N} / 130-140^{\circ} \mathrm{W}\right)$ that allows assessment of the series prior to the original calibration period. Over the $1898-2000$ period, the series correlates at 0.54 (Table 1) with June temperatures (the optimized climate parameter when using this extended gridded data set).

\section{A13. Northern Yukon}

[43] Szeicz and MacDonald [1995] used RW data from five Picea glauca chronologies in northwestern Canada to develop a June-July reconstruction back to 1638. Agedependent modeling was used to optimize the calibrated signal as well as capture more low-frequency variability in the final proxy time series. The original reconstruction was calibrated against local station data and explained $47 \%$ of the June-July variability. In this study, the correlation (r) of the record with local gridded June-July temperatures is 0.60 (Table 1).

\section{A14. Wrangell Mountains}

[44] Davi et al. [2003] developed a warm-season (JulySeptember) temperature reconstruction $(1593-1992)$ based on the first eigenvector from principal component analysis of six Picea glauca MXD chronologies (processed using standard techniques). Their reconstruction explained $51 \%$ of the temperature variance over the 1958-1992 calibration period. In this study, we derived a simple mean of the four longest chronologies from the Davi et al. [2003] study (ITRDB code: AK077, Caribou Creek $\left(62.33^{\circ} \mathrm{N} / 143.17^{\circ} \mathrm{W}\right)$, Nabesna Mine (AK074, $\left.62.22^{\circ} \mathrm{N} / 143.03^{\circ} \mathrm{W}\right)$, Big Bend Lake (AK078, $61.20^{\circ} \mathrm{N} / 142.43^{\circ} \mathrm{W}$ ) and Hawkins Hill (AK075, 61.09 ${ }^{\circ} \mathrm{N} /$ $\left.142.05^{\circ} \mathrm{W}\right)$ ) which allowed the series to be brought forward to 1997 . The resultant time series correlates optimally with July-August mean gridded temperatures at 0.63 over the extended period 1900-1995. It should be noted that Davi et al. [2003] also produced an eigenvector score from a RW chronology network in the region. The resultant PC (utilized by D'Arrigo et al. [2006]) although showing a similar temporal history to the MXD data, showed divergence since 1970 when compared to the instrumental data. Davi et al. [2003] stated that this might be related to increasing moisture stress or other factors.

\section{A15. Northern Quebec}

[45] It is obvious from Figure 2, that there is a spatial bias in the availability of relevant temperature sensitive TR data sets for North America. This is partly due to the geography of North America, with the mountains and resultant upper elevational tree line sites being mostly restricted to the west, but also reflects that the recently updated TR chronologies along the northern latitudinal tree line were utilized by D'Arrigo et al. [2006]. In the ITRDB, there are no archived TR chronologies, which express a temperature signal that go up to at least 1995 . Luckily, newly sampled data sets were obtained for Northern Quebec from Lake Tesialuk (Picea glauca, $1620-1997,58.23^{\circ} \mathrm{N} / 67.03^{\circ} \mathrm{W}$ ) and Pyramid Lake (Picea glauca, $1608-2002,57.27^{\circ} \mathrm{N} / 65.12^{\circ} \mathrm{W}$ [Payette, 2007]). These two chronologies were supplemented by RW data from Fort Chimo (Larix laricina, 1641-1974, 
$58.22^{\circ} \mathrm{N} / 68.23^{\circ} \mathrm{W}$, ITRDB code CANA002). The data from these three data sets were pooled and a regional northern Quebec chronology was developed (detrending using standard methods) with $>10$ series for the 1641-2002 period. This series correlates with gridded July temperatures at 0.42 over the 1942-2002 period (Table 1).

[46] Acknowledgments. R.W., U.B. and J.E. are funded by the European Community under research contract 017008-2 MILLENNIUM. R.D. and B.B. were funded by NOAA and by the National Science Foundation's Earth System History and Paleoclimatology programs. D.F. is funded by the Swiss National Science Foundation (NCCR-Climate). The Canadian studies were funded by the Natural Sciences and Engineering Research Council of Canada (B.L., D.Y. and S.P.) and Meteorological Service of Canada and the Inter-American Institute for Global Change Research (B.L. and D.Y.). We thank Philip Brohan and Andreas Kirchhefer (funded through MILLENNIUM) for informative discussions on this topic. This is Lamont-Doherty Earth Observatory contribution 7050.

\section{References}

Barber, V., G. Juday, and B. Finney (2000), Reduced growth of Alaska white spruce in the twentieth century from temperature-induced drought stress, Nature, 405, 668-672.

Biondi, F., D. L. Perkins, D. R. Cayan, and M. K. Hughes (1999), July temperature during the second millennium reconstructed from Idaho tree rings, Geophys. Res. Lett., 26, 1445-1448.

Briffa, K. (2000), Annual climate variability in the Holocene: Interpreting the message from ancient trees, Quat. Sci. Rev., 19, 87-105.

Briffa, K. R., and P. D. Jones (1990), Basic chronology statistics and assessment, in Methods of Dendrochronology: Applications in the Environmental Sciences, edited by E. R. Cook and L. A. Kairiukstis, pp. 137152, Springer, New York.

Briffa, K. R., P. D. Jones, T. S. Bartholin, D. Eckstein, F. H. Schweingruber, W. Karlén, P. Zetterberg, and M. Eronen (1992), Fennoscandian summers from A.D. 500: Temperature changes on short and long timescales, Clim. Dyn., 7, 111-119.

Briffa, K., F. Schweingruber, P. Jones, and T. Osborn (1998a), Reduced sensitivity of recent tree growth to temperature at high northern latitudes, Nature, 391, 678-682.

Briffa, K., F. Schweingruber, P. Jones, T. Osborn, I. Harris, S. Shiyatov, A. Vaganov, and H. Grudd (1998b), Trees tell of past climates: But are they speaking less clearly today?, Phil. Trans. R. Soc. Lond. Ser. B, 353, $65-73$.

Briffa, K. R., T. J. Osborn, F. H. Schweingruber, I. C. Harris, P. D. Jones, S. G. Shiyatov, and E. A. Vaganov (2001), Low frequency temperature variations from a northern tree-ring density network, Geophys, J., Res., 106, $2929-2941$

Briffa, K., T. Osborn, and F. Schweingruber (2004), Large-scale temperature inferences from tree rings: A review, Global Planet. Change, 40, $11-26$.

Brohan, P., J. J. Kennedy, I. Harris, S. F. B. Tett, and P. D. Jones (2006), Uncertainty estimates in regional and global observed temperature changes: A new data set from 1850, J. Geophys. Res., 111, D12106, doi:10.1029/2005JD006548.

Büntgen, U., J. Esper, D. C. Frank, K. Nicolussi, and M. Schmidhalter (2005), A 1052-year tree-ring proxy for Alpine summer temperatures, Clim. Dyn., 25, 141-153.

Büntgen, U., D. Frank, M. Schmidhalter, B. Neuwirth, M. Seifert, and J. Esper (2006a), Growth/climate response shift in a long subalpine spruce chronology, Trees, 20, 99-110.

Büntgen, U., D. C. Frank, D. Nievergelt, and J. Esper (2006b), Alpine summer temperature variations, AD 755-2004, J. Clim., 19, 5606-5623.

Büntgen, U., D. C. Frank, R. J. Kaczka, A. Verstege, T. Zwijacz-Kozica, and J. Esper (2007), Growth/climate response of a multi-species tree-ring network in the western Carpathian Tatra Mountains, Poland and Slovakia, Tree Physiol., 27, 689-702.

Bürger, G., I. Fast, and U. Cubasch (2006), Climate reconstruction by regression-32 variations on a theme, Tellus, Ser. A., 58, 227-235.

Carrer, M., and C. Urbinati (2006), Long-term change in the sensitivity of tree-ring growth to climate forcing in Larix decidua, New Phytol., 170, $861-872$.

Cook, E. R., and L. A. Kairiukstis (Eds.) (1990), Methods of Dendrochronology: Applications in the Environmental Sciences, 394 pp., Springer, New York.

Cook, E. R., K. R. Briffa, and P. D. Jones (1994), Spatial regression methods in dendroclimatology: A review and comparison of two techniques, Int. J. Climatol., 14, 379-402.
Cook, E., K. R. Briffa, D. M. Meko, D. A. Graybill, and G. Funkhouser (1995), The "segment length curse" in long tree-ring chronology development for paleoclimatic studies, Holocene, 5, 229-237.

Cook, E. R., R. D. D'Arrigo, and M. E. Mann (2002), A well-verified, multiproxy reconstruction of the Winter North Atlantic Oscillation Index since A. D. 1400, J. Clim., 15, 1754-1764.

Cook, E. R., P. J. Krusic, and P. D. Jones (2003), Dendroclimatic signals in long tree-ring chronologies from the Himalayas of Nepal, Int. J. Climatol., 23, 707-732.

Cook, E., J. Esper, and R. D'Arrigo (2004), Extra-tropical Northern Hemisphere land temperature variability over the past 1000 years, Quat. Sci. Rev., 23, 2063-2074.

D’Arrigo, R. D., G. Jacoby, N. Pederson, D. Frank, B. Buckley, N. Baatarbileg, R. Mijiddorj, and C. Dugarjav (2000), Mongolian tree rings, temperature sensitivity and reconstructions of northern hemisphere temperature, Holocene, 10, 669-672.

D’Arrigo, R., G. Jacoby, D. Frank, N. Pederson, E. Cook, B. Buckley, R. Mijiddorj, and C. Dugarjav (2001), 1738 years of Mongolian temperature variability inferred from a tree-ring record of Siberian pine, Geophys. Res. Lett., 28, 543-546.

D'Arrigo, R. D., R. K. Kaufmann, N. Davi, G. C. Jacoby, C. Laskowski, R. B. Myneni, and P. Cherubini (2004), Thresholds for warming-induced growth decline at elevational tree line in the Yukon Territory, Canada, Global Biogeochem. Cycles, 18, GB3021, doi:10.1029/2004GB002249.

D'Arrigo, R., R. Wilson, and G. Jacoby (2006), On the long-term context for late twentieth century warming, J. Geophys. Res., 111, D03103, doi:10.1029/2005JD006352.

D'Arrigo, R., R. Wilson, B. Liepert, and P. Cherubini (2007), On the 'Divergence Problem' in northern forests: A review of the tree-ring evidence and possible causes, Global Planet. Change, in press.

Davi, N., R. D’Arrigo, G. Jacoby, B. M. Buckley, and O. Kobayashi (2002), Warm-season annual temperature variability for Hokkaido, Japan, reconstructed from tree-ring density data: AD 1557-1990, Clim. Change, 52, 201-217.

Davi, N., G. Jacoby, and G. Wiles (2003), Boreal temperature variability inferred from maximum latewood density and tree-ring width data, Wrangell Mountain region, Alaska, Quat. Res., 60, 252-262.

Driscoll, W., G. Wiles, R. D'Arrigo, and M. Wilmking (2005), Divergent tree growth response to recent climatic warming, Lake Clark National Park and Preserve, Alaska, Geophys. Res. Lett., 32, L20703, doi:10.1029/ 2005GL024258.

Easterling, D. R., et al. (1997), Maximum and minimum temperature trends for the globe, Science, 277, 364-367.

Esper, J., E. Cook, and F. Schweingruber (2002), Low-frequency signals in long tree-ring chronologies for reconstructing past temperature variability, Science, 295, 2250-2253.

Esper, J., E. R. Cook, P. J. Krusic, K. Peters, and F. H. Schweingruber (2003a), Tests of the RCS method for preserving low-frequency variability in long tree-ring chronologies, Tree Ring Res., 59, 81-98.

Esper, J., S. G. Shiyatov, V. S. Mazepa, R. J. S. Wilson, D. A. Graybill, and G. Funkhouser (2003b), Temperature-sensitive Tien Shan tree ring chronologies show multi-centennial growth trends, Clim. Dyn., 21, 699-706.

Esper, J., D. Frank, R. J. S. Wilson, and K. Briffa (2005), Effect of scaling and regression on reconstructed temperature amplitude for the past millennium, Geophys. Res. Lett., 32, L07711, doi:10.1029/2004GL021236.

Folland, C. K., et al. (2001), Global temperature change and its uncertainties since 1861, Geophys. Res. Lett., 28, 2621-2624.

Frank, D., and J. Esper (2005), Temperature reconstructions and comparisons with instrumental data from a tree-ring network for the European Alps, Int. J. Climatol., 25, 1437-1454.

Frank, D., D. Ovchinnikov, A. Kirdyanov, and J. Esper (2007), The potential for long-term climatic reconstructions in the western Altay Mountains from living and relict larch, in Tree Rings in Archaeology, Climatology and Ecology (TRACE), vol. 5., pp. 85-96, Forsch. Jülich GmbH, Jülich, Germany.

Gostev, M., G. Wiles, R. D’Arrigo, and G. Jacoby (1996), Temperature reconstruction for Kamchatka based on Siberian larch tree-ring data, Can. J. For. Res., 26, 2048-2052.

Hegerl, G. C., T. J. Crowley, M. Allen, W. T. Hyde, H. N. Pollack, J. Smerdon, and E. Zorita (2007), Detection of human influence on a new, validated 1500-year temperature reconstruction, J. Clim., 20(4), 650-666.

Intergovernmental Panel on Climate Change (2001), Climate Change 2001: The Scientific Basis, Summary for Policy Makers - Contribution of Working Group I to the Third Assessment Report of the Intergovernmental Panel on Climate Change, edited by J. T. Houghton et al., 881 pp., Cambridge Univ. Press, New York.

Intergovernmental Panel on Climate Change (2007), Climate Change 2007: The Physical Science Basis, Summary for Policy Makers, Boulder, Colo. (Available at http://ipcc-wg1.ucar.edu/wg1/wg1-report.html) 
Jacoby, G., and R. D'Arrigo (1989), Reconstructed northern hemisphere annual temperature since 1671 based on high latitude tree-ring data from North America, Clim. Change, 14, 39-59.

Jacoby, G. C., and R. D'Arrigo (1995), Tree-ring width and density evidence of climatic and potential forest change in Alaska, Global Biogeochem. Cycles, 9, 227-234.

Jacoby, G. C., R. D'Arrigo, and T. Davaajamts (1996), Mongolian tree rings and twentieth century warming, Science, 273, 771-773.

Jacoby, G., N. Lovelius, O. Shumilov, O. Raspopov, J. Kurbainov, and D. Frank (2000), Long-term temperature trends and tree growth in the Taymir region of northern Siberia, Quat. Res., 53, 312-318.

Jones, P., K. Briffa, T. Barnett, and S. Tett (1998), High-resolution paleoclimatic records for the last millennium: Interpretation, integration and comparison with General Circulation Model control-run temperatures, Holocene, 8, 455-471.

Karl, T. R., P. D. Jones, R. W. Knight, G. Kukla, N. Plummer, V. Razuvayev, K. P. Gallo, J. A. Lindsay, R. J. Charlson, and T. C. Peterson (1993), Asymmetric trends of daily maximum and minimum temperature, Bull. Am. Meteorol. Soc, 64, 1007-1023.

Kirchhefer, A. J. (2001), Reconstruction of summer temperatures from treerings of Scots pine (Pinus sylvestris L.) in coastal northern Norway, Holocene, 11, 41-52.

Lindholm, M., M. Timonen, and J. Meriläinen (1996), Extracting midsummer temperatures from ring-width chronologies of living pines at the northern forest limit in Fennoscandia, Dendrochronologia, 14, 99113.

Lloyd, A., and C. Fastie (2002), Spatial and temporal variability in the growth and climate response of treeline trees in Alaska, Clim. Change, $58,481-509$.

Luckman, B., and R. Wilson (2005), Summer temperatures in the Canadian Rockies during the last millennium-A revised record, Clim. Dyn., 24, $131-144$.

Mann, M. E., R. S. Bradley, M. K. Hughes, and P. D. Jones (1998), Global temperature patterns, Science, 280, 2029-2030.

Mann, M. E., S. Rutherford, E. Wahl, and C. Ammann (2005), Testing the fidelity of methods used in proxy-based reconstructions of past climate, J. Clim., 18, 4097-4107.

McIntyre, S., and R. McKitrick (2005), Hockey sticks, principal components, and spurious significance, Geophys. Res. Lett., 32, L03710, doi:10.1029/2004GL021750.

Meko, D. M. (1997), Dendroclimatic reconstruction with time varying subsets of tree indices, J. Clim., 10, 687-696.

Melvin, T. (2004), Historical growth rates and changing climatic sensitivity of boreal conifers, Ph. D. thesis, Climatic Res. Unit, Univ. of East Anglia, U. K.

Mitchell, V. (1967), An investigation of certain aspects of tree growth rates in relation to climate in the central Canadian boreal forest, Tech. Rep. 33, Dep. of Meteorology, Univ. of Wisconsin, Madison, Wis.

Moberg, A., H. Alexandersson, H. Bergström, and P. D. Jones (2003), Were southern Swedish summer temperatures before 1860 as warm as measured?, Int. J. Climatol., 23, 1495-1521.

Moberg, A., D. M. Sonechkin, K. Holmgren, N. M. Datsenko, and W. Karlen (2005), Highly variable Northern Hemisphere temperatures reconstructed from low- and high-resolution proxy data, Nature, 433, 613-617.

National Research Council (2006), Report on Surface Temperature Reconstructions for the Last 2,000 Years, Natl. Academies Press, Washington, D. C.

Osborn, T. J., K. R. Briffa, and P. D. Jones (1997), Adjusting variance for sample-size in tree-ring chronologies and other regional-mean time-series, Dendrochronologia, 15, 89-99.

Payette, S. (2007), Contrasted dynamics of northern Labrador tree lines caused by climate change and migrational lag, Ecology, 88, 770-780.

Payette, S., A. Delwaide, C. Morneau, and C. Lavoie (1996), Patterns of tree stem decline along a snow-drift gradient at treeline: A case study using stem analysis, Can. J. Bot., 74, 1671-1683.
Rutherford, S., M. E. Mann, T. J. Osborn, R. S. Bradley, K. R. Briffa, M. K. Hughes, and P. D. Jones (2005), Proxy-based northern hemisphere surface temperature reconstructions: Sensitivity to method, predictor network, target season, and target domain, J. Clim., 18, 2308-2329.

Salzer, M., and K. Kipfmueller (2005), Reconstructed temperature and precipitation on a millennial timescale from tree-rings in the southern Colorado plateau, U.S.A., Clim. Change, 70, 465-487, doi:10.1007/ s10584-005-5922-3.

Szeicz, J., and G. MacDonald (1995), Dendroclimatic reconstruction of summer temperatures in northwestern Canada since A. D. 1638 based on age-dependent modeling, Quat. Res., 44, 257-266.

Vaganov, E., M. Hughes, A. Kirdyanov, F. Schweingruber, and P. Silkin (1999), Influence of snowfall and melt timing on tree growth in subArctic Eurasia, Nature, 400, 149-151.

von Storch, H., E. Zorita, J. Jones, Y. Dimitriev, F. Gonzalez-Rouco, and S. Tett (2004), Reconstructing past climate from noisy data, Science, 306, 679-682.

von Storch, H., E. Zorita, J. M. Jones, F. Gonzalez-Rouco, and S. F. B. Tett (2006), Response to Comment on "Reconstructing Past Climate from Noisy Data", Science, 312, 529c.

Vose, R. S., D. R. Easterling, and B. Gleason (2005), Maximum and minimum temperature trends for the globe: An update through 2004, Geophys. Res. Lett., 32, L23822, doi:10.1029/2005GL024379.

Wilmking, M., G. Juday, V. Barber, and H. Zald (2004), Recent climate warming forces contrasting growth responses of white spruce at treeline in Alaska through temperature thresholds, Global Change Biol., 10, 1724-1736, doi:10.1111/j.1365-2486.2004.00826.

Wilmking, M., R. D’Arrigo, G. Jacoby, and G. Juday (2005), Divergent growth responses in circumpolar boreal forests, Geophys. Res. Lett., 32, L15715, doi:10.1029/2005GL023331.

Wilson, R., and W. Elling (2004), Temporal instability in tree-growth/climate response in the lower Bavarian forest region: Implications for dendroclimatic reconstruction, Trees, 18, 19-28.

Wilson, R., and B. Luckman (2002), Tree-ring reconstruction of maximum and minimum temperatures and the diurnal temperature range in British Columbia, Canada, Dendrochronologia, 20, 1-12.

Wilson, R. J. S., and B. H. Luckman (2003), Dendroclimatic reconstruction of maximum summer temperatures from upper tree-line sites in interior British Columbia, Holocene, 13, 853-863.

Wilson, R. J. S., and J. Topham (2004), Violins and climate, Theor. Appl. Climatol., 77, 9-24.

Wilson, R., G. Wiles, R. D'Arrigo, and C. Zweck (2007), Cycles and shifts: 1300 -years of multi-decadal temperature variability in the Gulf of Alaska, Clim. Dyn., 28, 425-440, doi:10.1007/s00382-006-0194-9.

Yonenobu, H., and D. Eckstein (2006), Reconstruction of early spring temperature for central Japan from the tree-ring widths of Hinoki cypress and its verification by other proxy records, Geophys. Res. Lett., 33, L10701, doi:10.1029/2006GL026170.

Youngblut, D. K., and B. H. Luckman (2007), Maximum June-July temperatures in the southwest Yukon region over the last three hundred years reconstructed from tree-rings, Dendrochronologia, in press.

B. Buckley and R. D'Arrigo, Lamont-Doherty Earth Observatory, 61 Route 9W, Palisades, NY 10964, USA.

U. Büntgen, J. Esper, and D. Frank, Swiss Federal Research Institute WSL, CH-8903 Birmensdorf, Switzerland.

B. Luckman, Department of Geography, University of Western Ontario, London, ON, Canada N6A 5C2.

S. Payette, Centre d'Études Nordiques, Université Laval, Québec, QC, Canada G1K 7P4.

R. Vose, National Climatic Data Center, Asheville, NC 28801, USA.

R. Wilson, Grant Institute, University of Edinburgh, West Mains Road, Edinburgh EH9 3JW, UK. (rob.wilson@ed.ac.uk)

D. Youngblut, Department of Geography and Environmental Studies, Carleton University, Ottawa, ON, Canada K1S 5B6. 